\title{
The highly rearranged mitochondrial genomes of three economically important scale insects and the mitochondrial phylogeny of Coccoidea (Hemiptera: Sternorrhyncha)
}

\author{
Hong-Ling Liu ${ }^{1}$, Qing-Dong Chen ${ }^{1}$, Song Chen ${ }^{1}$, De-Qiang Pu ${ }^{1}$, Zhi-Teng Chen ${ }^{2}$, Yue-Yue Liu ${ }^{3}$, Xu Liu ${ }^{\text {Corresp. } 1}$ \\ ${ }^{1}$ Institute of plant protection, Sichuan Academy of Agricultural Sciences, Key Laboratory of integrated pest management of Southwest crops, Ministry of \\ Agriculture, Chengdu, China \\ 2 School of Grain Science and Technology, Jiangsu University of Science and Technology, Zhenjiang, China \\ 3 Analysis and testing center of Sichuan Academy of Agricultural Sciences, Chengdu, China \\ Corresponding Author: Xu Liu \\ Email address: liuxu6186@126.com
}

The mitochondrial genomes (mitogenomes) of scale insects are less known in comparison to other insects, which hinders the phylogenetic and evolutionary studies of Coccoidea and higher taxa. Herein, the complete mitogenomes of Unaspis yanonensis, Planococcus citri and Ceroplastes rubens were sequenced for Coccoidea. The 15,220-bp long mitogenome of $U$. yanonensis contained the typical set of 37 genes including 13 PCGs, 22 tRNA genes and two rRNA genes; the 15,549-bp long mitogenome of $P$. citri lacked the tRNA gene trnV; the 15,387-bp long mitogenome of $C$. rubens exhibited several shortened PCGs and lacked five tRNA genes. The mitochondrial gene arrangement of the three mitogenomes was different from other scale insects and Drosophila yakuba. Most PCGs used standard ATN (ATA, ATT, ATC and ATG) start codons and complete TAN (TAA or TAG) termination codons. The ND4L had the highest evolutionary rate but COX1 and CYTB were the lowest. Most tRNA genes had cloverleaf secondary structures, whereas the reduction of dihydrouridine (DHU) arms and TyC arms were detected. Tandem repeats, stem-loop (SL) structures and poly-[TA]n stretch were found in the control regions (CRs) of the three mitogenomes. The phylogenetic analyses using Bayesian inference (BI) and maximum likelihood methods $(\mathrm{ML})$ showed identical results, both supporting the inner relationship of Coccoidea as Coccidae + (Pseudococcidae + Diaspididae). 
1 The highly rearranged mitochondrial genomes of three

2 economically important scale insects and the mitochondrial

3 phylogeny of Coccoidea (Hemiptera: Sternorrhyncha)

6 Hong-Ling Liu ${ }^{1}$, Qing-Dong Chen ${ }^{1}$, Song Chen ${ }^{1}$, De-Qiang Pu ${ }^{1}$, Zhi-Teng Chen ${ }^{2}$, Yue-Yue Liu $7^{3}, \mathrm{Xu} \mathrm{Liu}{ }^{1}$

$9{ }^{1}$ Institute of plant protection, Sichuan Academy of Agricultural Sciences, Key Laboratory of integrated pest management of Southwest crops, Ministry of Agriculture, Chengdu 610066, China 2 School of Grain Science and Technology, Jiangsu University of Science and Technology,

12 Zhenjiang 212004, China

3 Analysis and testing center of Sichuan Academy of Agricultural Sciences, Chengdu 610066, China

Corresponding Author:

$\mathrm{Xu} \mathrm{Liu}^{1}$

Jingjusi Road, Chengdu, Sichuan, 610066, China

Email address: liuxu6186@126.com

\section{Abstract}

The mitochondrial genomes (mitogenomes) of scale insects are less known in comparison to other insects, which hinders the phylogenetic and evolutionary studies of Coccoidea and higher taxa. Herein, the complete mitogenomes of Unaspis yanonensis, Planococcus citri and Ceroplastes rubens were sequenced for Coccoidea. The 15,220-bp long mitogenome of U. yanonensis contained the typical set of 37 genes including 13 PCGs, 22 tRNA genes and two rRNA genes; the 15,549-bp long mitogenome of $P$. citri lacked the tRNA gene trn $V$; the 15,387-bp long mitogenome of $C$. rubens exhibited several shortened PCGs and lacked five tRNA genes. The 
mitochondrial gene arrangement of the three mitogenomes was different from other scale insects and Drosophila yakuba. Most PCGs used standard ATN (ATA, ATT, ATC and ATG) start codons and complete TAN (TAA or TAG) termination codons. The ND4L had the highest evolutionary rate but $C O X 1$ and $C Y T B$ were the lowest. Most tRNA genes had cloverleaf secondary structures, whereas the reduction of dihydrouridine (DHU) arms and T $\psi \mathrm{C}$ arms were detected. Tandem repeats, stem-loop (SL) structures and poly-[TA]n stretch were found in the control regions (CRs) of the three mitogenomes. The phylogenetic analyses using Bayesian inference (BI) and maximum likelihood methods (ML) showed identical results, both supporting the inner relationship of Coccoidea as Coccidae + (Pseudococcidae + Diaspididae $)$.

\section{Introduction}

The scale insects (Coccoidea) are well-known sap-sucking hemipterans which are economically important pests causing severe damage to native crops and plants (Kondo et al., 2008). Adult males of Coccoidea are hyperpaurometamorphosis, whereas the adult females are paurometamorphosis and resemble their nymphs (Gullan \& Kosztarab, 1997). These insects are usually smaller than 5 $\mathrm{mm}$ and often appear similar color with their host plants. Most scale insects can produce waxy secretion covering their bodies as a protection armature (Gullan \& Kosztarab, 1997), which also causes difficulty in using chemical control methods.

When compared with other superfamilies of the monophyletic suborder Sternorrhyncha: Aphidoidea (aphids), Aleyrodoidea (whiteflies) and Psylloidea (jumping plant lice), the superfamily Coccoidea possess a higher biodiversity and morphological variety (Gullan \& Martin, 2003; Gullan \& Cook, 2007). Despite of the previous morphological and molecular contributions (Koteja, 1974; von Dohlen \& Moran, 1995; Gullan \& Cook, 2007; Cook et al., 2007; Hodgson \& Hardy 2013), the scale insect systematics especially the family-level classification still remains unresolved.

Morphology of scale insects has apparent limits when used for resolving the higher-level phylogeny of scale insects, which is expected to be improved by the DNA sequence data. Mitochondrial genome (mitogenome) usually contains a typical set of 37 genes: 13 protein-coding genes (PCG), 22 transfer RNA genes (tRNA), two ribosomal RNA genes (rRNA) and a non-coding control region (CR) and has become one of the most popular molecules used in insect phylogenetic studies (Cameron, 2014). Recently, Deng et al. (2019) and Lu et al. (2020) respectively sequenced 
60 the mitogenomes of the two scale insects, Ceroplastes japonicus Green, 1921 and Saissetia coffeae

61 (Walker, 1852) and investigated the efficiency of using mitogenome data in the phylogeny of

62 Sternorrhyncha. Mitochondrial gene rearrangement and truncation of tRNA genes have been found

63 in the two mitogenomes. To facilitate the resolution of phylogeny and molecular evolution of

64 Coccoidea, we sequenced the complete mitogenomes of Unaspis yanonensis (Kuwana, 1923), Planococcus citri (Risso, 1813) and Ceroplastes rubens Maskell, 1893, which includes the first representatives of Pseudococcidae and Diaspididae. The mitogenomic organizations, gene rearrangements, nucleotide compositions, codon usages of PCGs, secondary structures of tRNA genes and CR were analyzed for the three mitogenomes. In addition, the phylogenetic relationships of four species of Coccoidea were reconstructed to evaluate the validity of the newly obtained molecular data.

\section{Materials \& Methods}

\section{Sample preparation and DNA extraction}

The specimens of $U$. yanonensis, $P$. citri and C. rubens were collected from Chengdu, Sichuan Province of China in October of 2019. The specimens were reliably identified by experts of Sichuan Academy of Agricultural Sciences, and were preserved in 100\% ethanol. The total genomic DNA of the three scale insects was isolated using the E.Z.N.A. ${ }^{\circledR}$ Tissue DNA Kit (OMEGA, America) and preserved at $-20^{\circ} \mathrm{C}$ before the sequencing process.

\section{Sequencing, assembly and annotation}

The Illumina TruSeq short-insert libraries (insert size $=450 \mathrm{bp}$ ) were constructed using $1.0 \mu \mathrm{g}$ of purified DNA fragments and sequenced by Illumina Hiseq 4000 (Shanghai BIOZERON Co., Ltd). Prior to assembly, raw reads were filtered and high-quality reads were retained and assembled into contigs by SOAPdenovo2.04 (Luo et al., 2012). Then the assembled contigs were aligned to the reference mitogenome of $C$. japonicus (GenBank accession number MK847519) using BLAST. The aligned contigs ( $\geq 80 \%$ similarity and query coverage) were arranged according to the reference mitogenome. Finally, the clean reads were mapped to the assembled draft mitogenome to fix the wrong bases; gaps were filled using GapFiller v2.1.1 (https://sourceforge.net/projects/gapfiller/). The mitogenome sequences of $U$. yanonensis, $P$. citri and $C$. rubens were deposited in GenBank under the accession numbers MT611525, MT611526 
and MT677923, respectively.

Most tRNA genes were predicted and depicted by MITOS (Bernt et al., 2013); structures of several tRNA genes of $C$. rubens were predicted manually. PCGs and rRNA genes were identified by homology alignments. Gene boundaries of PCGs were confirmed in ORF finder (https://www.ncbi.nlm.nih.gov/orffinder/). The graphic view of the mitogenomes were computed using CGView Server (http://stothard.afns.ualberta.ca/cgview_server/) (Grant \& Stothard 2008). The probable mitochondrial rearrangement scenarios during the evolution of $U$. yanonensis, $P$. citri and C. rubens were predicted by the CREx (Common Interval Rearrangement Explorer) online server (Bernt, 2007) using Drosophila yakuba as a reference (Clary \& Wolstenholme, 1985). Nucleotide composition of each gene and codon usage of PCGs were calculated by MEGA v.6.0 (Tamura et al., 2013). The composition skew analysis was conducted by AT-skew $=[\mathrm{A}-$ $\mathrm{T}] /[\mathrm{A}+\mathrm{T}]$ and $\mathrm{GC}-$ skew $=[\mathrm{G}-\mathrm{C}] /[\mathrm{G}+\mathrm{C}]$ formulas $($ Perna \& Kocher, 1995). The software DnaSP v. 5.10 (Librado \& Rozas, 2009) was used to calculate the synonymous substitution rate (Ks) and the nonsynonymous substitution rate $(\mathrm{Ka})$. Presumed secondary structures in the control region were predicted by the online tool Tandem Repeats Finder (http://tandem.bu.edu/trf/trf.advanced.submit.html) and DNAMAN v6.0.3.

\section{Phylogenetic analysis}

Nucleotide sequences of PCGs derived from four species of Coccoidea, including U. yanonensis, P. citri and C. rubens sequenced in this study, were used in the phylogenetic analysis (Table 1). The species $S$. coffeae was not included in the dataset due to the unannotated and unreliable status of its sequence as noted in Genbank. The two aphids, Aphis glycines and Diuraphis noxia were used as the outgroups. The 13 PCGs were aligned by MAFFT and concatenated as a combined dataset using SequenceMatrix v1.7.8 (Katoh \& Standley, 2013). PartitionFinder v2.1.1 was used to determine the optimal nucleotide substitution models and partitioning schemes by using the Bayesian Information Criterion (BIC) and a greedy search algorithm (Lanfear at al., 2016). Two phylogenetic inferences were conducted with the partition schemes, including Bayesian inferences (BI) and Maximum likelihood (ML) analysis. BI analysis was conducted by MrBayes v3.2.7, with 10 million generations sampling every 1000 generations, running one cold chain and three hot chains with a burn-in of $25 \%$ trees (Ronquist \& Huelsenbeck, 2003). Stability of the results of BI analysis were examined by Tracer v.1.5. ML analysis was performed by RAxML v8.2.12 with 
1221000 bootstrap replicates (Stamatakis, 2014). Tree files generated by both BI and ML trees were

123 adjusted and visualized in FigTree v1.4.2.

124

125

126

127

128

129

130

131

132

133

134

135

136

137

138

139

140

141

142

143

144

145

146

147

148

149

150

151

152

\section{Results}

\section{Mitogenome annotation and nucleotide composition}

The complete mitogenomes of $U$. yanonensis, $P$. citri and $C$. rubens were all typical double-strand circular molecules with a length of $15,220 \mathrm{bp}, 15,549 \mathrm{bp}$ and 15,387 bp, respectively (Fig. 1), which were similar to other mitogenomes of Coccoidea (Deng et al., 2019; Lu et al., 2020). The standard set of 37 genes (13 PCGs, 22 tRNA genes and two rRNA genes) were all found in the mitogenome of $U$. yanonensis (Table 2), whereas trnV was lost in P. citri (Table 3); C. rubens lacked five tRNA genes, $\operatorname{trn} C, \operatorname{trn} R, \operatorname{trnS} 2, \operatorname{trn} L 1$ and $\operatorname{trn} V$ (Table 4). In U. yanonensis, there were nine overlapping nucleotides located in four pairs of neighboring genes (Table 2); while in P. citri, there were 36 overlapping nucleotides in nine gene boundaries (Table 3). In C. rubens, there were only seven overlapping nucleotides in four gene boundaries (Table 4). The longest overlap was 18-bp long and located between trnS2 and ND1 in P. citri. There were 227 intergenic nucleotides (IGNs) dispersed in 20 locations for U. yanonensis, 126 IGNs in 19 locations for P. citri and 478 IGNs in 19 locations for C. rubens, indicating a loose structure of the three scale insect mitogenomes.

The whole mitogenomes of $U$. yanonensis, $P$. citri and C. rubens were strongly biased toward A and T nucleotides $(86.6 \%, 82.7 \%$ and $87.5 \%$, respectively). The $U$. yanonensis mitogenome had negative AT-skew and positive GC-skew, whereas P. citri and C. rubens exhibited positive ATskew and negative GC-skew. The $\mathrm{A}+\mathrm{T}$ contents were also rich in the mitochondrial genes, showing the highest in $\operatorname{trnF}$ of $U$. yanonensis and P. citri, and trnG of C. rubens.

\section{Gene rearrangement}

The mitochondrial genes of $U$. yanonensis, $P$. citri and C. rubens were highly rearranged, being different from the two sequenced scale insects, C. japonicus and S. coffeae (Deng et al., 2019; Lu et al., 2020). When compared with D. yakuba, U. yanonensis and P. citri both showed a conserved gene cluster trnE-trnF-ND5-trnH-ND4-ND4l-trnT-trnP-ND6-CYTB-trnS2-ND1-trnL1-rrnL; C. rubens had three shorter conserved gene clusters, COX1-trnL-COX2-trnK-trnD, COX3-trnG-ND3 and ND5-trnH-ND4-ND4L (Fig. 2). The mitogenome of $U$. yanonensis exhibited the 
153

154

155

156

157

158

159

160

161

162

163

164

165

166

167

168

169

170

171

172

173

174

175

176

177

178

179

180

181

182

183

rearrangement of three cytochrome c oxidase subunit genes (COX1,COX2,COX3), two NADH dehydrogenase subunit genes (ND2 and ND3) and many tRNA genes. Despite of the multiple tRNA gene rearrangements, the mitogenome of $P$. citri also had a reversal of the ancestral gene cluster COX1-COX2-ATP8-ATP6-COX3- ND3. The mitogenome of C. rubens showed fewer rearrangements than $U$. yanonensis and P. citri, including two PCGs (ND2 and ATP8) and multiple tRNA genes.

The CREx analysis predicted the alternative scenarios how the three scale insect mitogenomes rearranged from the ancestral type of mitogenome of $D$. yakuba (Fig. 3, 4, 5). The mitochondrial gene order of $U$. yanonensis changed from $D$. yakuba by nine steps of rearrangement events, including the transposition of $\operatorname{trn} V$ and $\operatorname{rrnS}$, the subsequent reverse transposition of $\operatorname{trnK}$

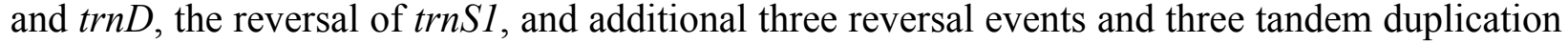
and random loss (TDRL) events (Fig. 3). In P. citri, the first step is the reversal of trnK, followed by two alternative scenarios: the first one contained two reversal events, one TDRL event and one transposition event; the second one included three reversal events, two TDRL events and one transposition event (Fig. 4). Fewer rearrangement events were predicted in C. rubens, including the first step of transposition, the subsequent three reversal events, and final three TDRL events (Fig. 5). Considering the similarly rearranged mitochondrial genes of C. japonicus and $S$. coffeae, extensive mitochondrial rearrangement events are expected to occur very frequently in other unsequenced scale insects.

\section{Protein-coding genes}

The 13 PCGs of $U$. yanonensis were similar in size to those of $P$. citri, without truncated or duplicated PCGs (Table 2, Table 3). However, most PCGs of $C$. rubens were shorter than $U$. yanonensis and P. citri, especially for ATP8 and ND6 (Fig. 6). Most PCGs of the three mitogenomes utilized the standard ATN start codon (ATA, ATT, ATC and ATG). However, the special start codon TTG was used by COX1 of $U$. yanonensis (Table 2). Twelve PCGs of each mitogenome had the complete termination codon TAN (TAA or TAG), whereas ND6 of $U$. yanonensis and $P$. citri and $C O X 2$ of $C$. rubens ended with an incomplete stop codon T. In the

previously sequenced scale insect, C. japonicus, COX2 also ended with an incomplete T (Deng et al., 2019). The relative synonymous codon usage (RSCU) values were calculated for the three mitogenomes (Fig. 7). In U. yanonensis, the most frequently used codon was TTA (Leu) whereas 
184

185

186

187

188

189

190

191

192

193

194

195

196

197

198

199

200

201

202

203

204

205

206

207

208

209

210

211

212

213

214

CTG(Leu), TCC(Ser), ACC(Thr), ACG(Thr), GCC(Ala), CAG(Gln), TGC(Cys), CGG(Arg) and AGC(Ser) were not used. In P. citri, the mostly used codon was also TTA (Leu), but CTC (Leu), AGC (Ser) and CGC (Arg) were the least. In C. rubens, TTA (Leu) was the most frequently used codon.

To evaluate the evolutionary rates of the PCGS, the average ratio of $\mathrm{Ka} / \mathrm{Ks}$ was calculated for each PCG of the three mitogenomes (Fig. 8). The results showed that ND4L had the highest evolutionary rate, followed by ATP8 and ND5, while COX1 and CYTB appeared to be the lowest. The ratios of $\mathrm{Ka} / \mathrm{Ks}$ were above 1 for most PCGs except for $C O X 1$ and $C Y T B$, suggesting that these genes are evolving under positive selection. However, the ratios of $\mathrm{Ka} / \mathrm{Ks}$ for $C O X 1$ and $C Y T B$ were below 1, indicating the purifying selection in these genes. The two genes, $C O X 1$ and $C Y T B$ which with relatively slow evolutionary rates have already been used as efficient phylogenetic markers in insects.

\section{Transfer RNA genes}

The typical set of 22 tRNA genes were all detected in the mitogenome of $U$. yanonensis, but trn $V$ was absent from the mitogenome of $P$. citri (Fig. 9, 10). In C. rubens, only 17 tRNA genes were recognized and the three tRNA genes $\operatorname{trn} A, \operatorname{trn} Q$ and $\operatorname{trn} W$ were manually predicted (Fig. 11). Length and $\mathrm{A}+\mathrm{T}$ content of the tRNA genes were subequal between $U$. yanonensis and P. citri, whereas the lengths of tRNA genes of $C$. rubens were generally shorter than $U$. yanonensis and $P$. citri. Individual tRNA gene of the three mitogenomes ranged in size from 49 to $75 \mathrm{bp}$; the longest tRNA gene was trnA in P. citri (Table 3); the shortest tRNA gene was trnY in C. rubens (Table 4). In the mitogenomes of $U$. yanonensis and P. citri, most of the tRNA genes could fold into cloverleaf secondary structures, but the dihydrouridine (DHU) arms of trnR and trnSl were consistently lost. In C. rubens, most tRNA genes exhibited reduced DHU arms or T $\psi C$ arms. Such reductions of DHU arms were also reported in the tRNA genes of S. coffeae ( $\mathrm{Lu}$ et al., 2020), suggesting that tRNA gene reduction could be a very common phenomenon in the mitogenomes of scale insects. The anticodons of the tRNA genes were identical among the three scale insects. In the tRNA genes of $U$. yanonensis and P. citri, a total of 12 and 19 mismatched base pairs were respectively identified and all of them were G-U pairs. In C. rubens, only four mismatched G-U pairs were identified. 


\section{Ribosomal RNA genes}

216 There were two rRNA genes identified in in each mitogenome. The length and A+T content of

217

218

219

220

221

222

223

224

225

226

227

228

229

230

231

232

233

234

235

236

237

238

239

240

241

242

243 each rRNA gene were subequal between $U$. yanonensis and $P$. citri, but the lengths of rRNA genes were much shorter in C. rubens (Table 2, Table 3, Table 4). In U. yanonensis, the large ribosomal RNA ( $r r n L)$ gene was 1314 bp with an A+T content of 89.6\%; the small ribosomal RNA ( $r r n S$ ) gene was 807 bp with a high A+T content of 90.6\%. In P. citri, the rrnL gene was 1396 bp with an $\mathrm{A}+\mathrm{T}$ content of $86.9 \%$; the $r r n S$ gene was 856 bp with an $\mathrm{A}+\mathrm{T}$ content of $88.4 \%$. In $C$. rubens, the $r r n L$ gene was 1263 bp with a high A+T content of $90.7 \%$; the $r r n S$ gene was 587 bp with an $\mathrm{A}+\mathrm{T}$ content of $87.9 \%$. Locations of the two rRNA genes were similar to $D$. yakuba, being neighbored with the CYTB-ND1 PCG cluster (Fig. 2). Instead of the commonly found trnV between the $r r n L$ and $r r n S$ genes in other insects, the intermediate tRNA gene between the two rRNA genes was trnA in $U$. yanonensis, $\operatorname{trn} A$ and $\operatorname{trn} Q$ in $P$. citri, and completely absent in $C$. rubens.

\section{Control region}

Control region (CR), also known as $\mathrm{A}+\mathrm{T}$ rich region, was the longest and most variable non-coding area in the three mitogenomes (Fig. 12). The CR of $U$. yanonensis was short with only $260 \mathrm{bp}$, being located between $\operatorname{trn} Y$ and $A T P 8$ and with a relatively high A+T content of $81.9 \%$ (Table 2). The CR of $P$. citri was much longer than $U$. yanonensis (678 bp), being located between trnM and trnI and with an A+T content of $84.4 \%$ (Table 3). Two putative CRs were found in the mitogenome of C. rubens: the 830-bp long CR1 between $r r n S$ and $\operatorname{trnF}$ and the 800-bp long CR2 between trnF and trnM (Table 4). A+T content of the two CRs was $85.4 \%$ and $88.4 \%$, respectively, higher than U. yanonensis and P. citri. The CR of C. japonicus and S. coffeae was $507 \mathrm{bp}$ and $1454 \mathrm{bp}$, respectively, indicating the highly variable length of CRs in scale insects (Deng et al., 2019; Lu et al., 2020).

The CR of $U$. yanonensis was composed of 2.9 copies of tandem repeats; the first two copies had a consensus size of $91 \mathrm{bp}$, whereas the third repeat was $78 \mathrm{bp}$ in length. The CR of $P$. citri contained three types of secondary structures that might function in regulating the replication and transcription of the mitogenome, including 2.3 copies of 110-bp long tandem repeats, one 40-bp long poly-[TA]n stretch, and a 21-bp long stem-loop (SL) structure. The SL structure was initiated by a "TAA" motif and ended with a "GTA" motif. The longer tandem repeats and extra secondary 
246

247

248

249

250

251

252

253

254

255

256

257

258

259

260

261

262

263

264

265

266

267

268

269

270

271

272

273

274

275

structures of $P$. citri resulted in the longer CR than that of $U$. yanonensis. The CR1 of C. rubens contained 3.6 copies of 33-bp long tandem repeats but had no SL structures. The CR2 of C. rubens included 5 copies of 24-bp long tandem repeats and a combined SL structure. The length, nucleotide composition, number and types of structural elements in CRs of the three mitogenomes were found highly variable, which implied that the scale insect mitogenomes were likely to be regulated in different ways during the mitogenomic replication and transcription processes.

\section{Discussion}

To test the reliability of the three sequenced mitogenomes and investigate the mitochondrial phylogenetic relationships within Coccoidea, nucleotide sequences of available scale insects were obtained from GenBank and used in the phylogenetic analyses (Table 1). The two phylogenetic trees using BI and ML analyses generated identical topological structures for Coccoidea (Fig. 13). The three families of Coccoidea were grouped together, suggesting the probable monophyly of Coccoidea as found in von Dohlen \& Moran (1995), which used the small-subunit (18S) ribosomal DNA in the phylogenetic analysis. The monophyly of Coccidae was supported with high values, indicating the efficiency of mitogenome data in grouping members of the same family and partially supporting the correctness of the tree topologies. Pseudococcidae was recovered as the sister group of Diaspididae and the phylogenetic position of their combined clade was supported basal to Coccidae. However, in previous molecular and morphological studies (Gullan \& Cook, 2007; Cook et al., 2007; Hodgson \& Hardy 2013), Pseudococcidae was supported basal to Coccidae and Diaspididae. The insufficient mitogenome data of Coccoidea, and the selection of different taxa and different molecular markers in the phylogenetic analysis were very likely to cause different phylogenetic results especially for the family levels (Chen et al., 2018). The new mitogenome data obtained in this study provided a basis for the accurate reconstruction of mitochondrial phylogeny in Coccoidea. The sequencing of more scale insects in future can also provide new data for our understanding of the highly rearranged mitogenomes and evolutionary history of these enigmatic insects. Sufficient representatives and molecular data will furtherer resolve the inner relationship of Coccoidea. 
276

277

278

279

280

281

282

283

284

285

286

287

288

289

290

291

292

293

294

295

296

297

298

299

300

301

302

\section{Conclusions}

The complete mitochondrial genomes of $U$. yanonensis, $P$. citri and $C$. rubens were sequenced and analyzed. The mitochondrial genes of the three scale insects were highly rearranged and different from other scale insects. The phylogenetic reconstructions with BI and ML methods generated identical phylogenetic topology and supported the inner relationship of Coccoidea as Coccidae + (Pseudococcidae + Diaspididae). More mitogenomes should be obtained in future works to resolve the phylogeny of scale insects.

\section{Acknowledgements}

The authors thank the editor (Mikhail Gelfand) and reviewers (Nina Voronova and another anonymous reviewer) for valuable comments and improvement of the manuscript. This research was supported by the National Key R \& D Program of China (No. 2017YFD0202002), Research on green pest control technology of characteristic fruit (No. 2016GYSH-018), and Sichuan fruit innovation team of national modern agricultural industry technology system (No. 2019-2023).

\section{References}

Bernt M. 2007. CREx: inferring genomic rearrangements using common intervals. Bioinformatics 23: $2957-2958$.

Bernt M, Donath A, Jühling F, Externbrink F, Florentz C, Fritzsch G, Pütz J, Middendorf M, Stadler PF. 2013. MITOS: Improved de novo metazoan mitochondrial genome annotation. Molecular Phylogenetics and Evolution 69:313-319.

Clary DO, Wolstenholme DR. 1985. The mitochondrial DNA molecule of Drosophila yakuba: nucleotide sequence, gene organization, and genetic code. Journal of Molecular Evolution 22(3):252-271.

Cook LG, Gullan PJ, Trueman HE. 2002. A preliminary phylogeny of the scale insects (Hemiptera: Sternorrhyncha: Coccoidea) based on nuclear small-subunit ribosomal DNA. Molecular Phylogenetics and Evolution 25(1):43-52. 
303

304

305

306

307

308

309

310

311

312

Cameron SL. 2014. Insect mitochondrial genomics: implications for evolution and phylogeny. Annual Review of Entomology 59:95-117.

Chen ZT, Zhao MY, Xu C, Du YZ. 2018. Molecular phylogeny of Systellognatha (Plecoptera: Arctoperlaria) inferred from mitochondrial genome sequences. International Journal of Biological Macromolecules 111:542-547.

Deng J, Lu C, Huang X. 2019. The first mitochondrial genome of scale insects (Hemiptera: Coccoidea). Mitochondrial DNA Part B 4:2, 2094-2095.

Green EE. 1921. Observations on British Coccidae: with descriptions of new species. VII. Entomologist's Monthly Magazine 57:257-259.

Gullan PJ, Cook LG. 2007. Phylogeny and higher classification of the scale insects (Hemiptera: Sternorrhyncha: Coccoidea). Zootaxa 1668(1):413-425.

Gullan PJ, Kosztarab M. 1997. Adaptations in scale insects. Annual Review of Entomology 42:23-50.

Gullan PJ, Martin JH. 2003. Sternorrhyncha (jumping plant-lice, whiteflies, aphids and scale insects). In: Resh VH, Cardé RT, eds. Encyclopedia of Insects. Amsterdam: Academic Press, 1079-1089.

Hodgson CJ, Hardy NB. 2013. The phylogeny of the superfamily Coccoidea (Hemiptera: Sternorrhyncha) based on the morphology of extant and extinct macropterous males. Systematic Entomology 38(4):794-804.

Kuwana I. 1923. Descriptions and biology of new or little known coccids from Japan. Department of Agriculture and Commerce, Imperial Plant Quarantine Station Bulletin 3:1-67.

Koteja J. 1974. Comparative studies on the labium in the Coccinea (Homoptera). Zeszyty Nankowe Akademii Rolniczej w Warszawie. Rozprawy Naukowe 89:1-162.

Katoh K, Standley DM. 2013. MAFFT multiple sequence alignment software version 7: improvements in performance and usability. Molecular Biology and Evolution 30:772-780.

Kondo T, Gullan PJ, Williams DJ. 2008. Coccidology. The study of scale insects (Hemiptera: Sternorrhyncha: Coccoidea). Ciencia y Tecnología Agropecuaria 9(2): 55-61. 
330

331

332

333

334

335

336

337

338

339

340

341

342

343

344

345

346

347

348

349

350

351

352

353

354

355

356

Lu C, Huang X, Deng J. 2020. The challenge of Coccidae (Hemiptera: Coccoidea) mitochondrial genomes: The case of Saissetia coffeae with novel truncated tRNAs and gene rearrangements. International Journal of Biological Macromolecules 158:854-864.

Librado P, Rozas J. 2009. DnaSP v5: a software for comprehensive analysis of DNA polymorphism data. Bioinformatics 25:1451-1452.

Lanfear R, Frandsen PB, Wright AM, Senfeld T, Calcott B. 2016. PartitionFinder 2: new methods for selecting partitioned models of evolution for molecular and morphological phylogenetic analyses. Molecular Biology and Evolution 34:772-773.

Luo RB, Liu BH, Xie YL, Li Z, Huang W, Yuan J, He G, Chen Y, Pan Q, Liu Y, Tang J, Wu G, Zhang H, Shi Y, Liu Y, Yu C, Wang B, Lu Y, Han C, Cheung DW, Yiu SM, Peng S, Xiaoqian Z, Liu G, Liao X, Li Y, Yang H, Wang J, Lam TW, Wang J. 2012. SOAPdenovo2: an empirically improved memory-efficient short-read de novo assembler. GigaScience 1:1-18.

Maskell WM. 1893. Further coccid notes: with descriptions of new species from Australia, India, Sandwich Islands, Demerara, and South Pacific. Transactions and proceedings of the New Zealand Institute 25(26):201-252.

Perna NT, Kocher TD. 1995. Patterns of nucleotide composition at fourfold degenerate sites of animal mitochondrial genomes. Journal of Molecular Evolution 41:353-358.

Risso A. 1813. Mémoire sur l'histoire naturelle des oranges, bigaradiers, limettiers, cédratiers limoniers ou citroniers, cultivés dans le départment des alpes maritimes. Annales du Muséum National d'Histoire Naturelle 20:401-431.

Ronquist F, Huelsenbeck JP. 2003. MrBayes 3: Bayesian phylogenetic inference under mixed models. Bioinformatics 19:1572-1574.

Stamatakis A. 2014. RAxML version 8: a tool for phylogenetic analysis and postanalysis of large phylogenies. Bioinformatics 30:1312-1313.

Tamura K, Stecher G, Peterson D, Filipski A, Kumar S. 2013. MEGA6: molecular evolutionary genetics analysis version 6.0. Molecular Biology and Evolution 30:2725-2729. 
357 358

von Dohlen CD, Moran NA. 1995. Molecular phylogeny of the Homoptera: a paraphyletic taxon. Journal of Molecular Evolution 41(2):211-223.

Walker F. 1852. List of the specimens of homopterous insects in the collection of the British Museum, Part IV. London: British Museum (Natural History). 
362

363

364

365

366

367

368

369

370

371

372

373

374

375

376

377

378

379

380

381

382

383

384

385

386

387

388

\section{Figure Captions}

Fig. 1. Mitochondrial maps of Unaspis yanonensis, Planococcus citri and Ceroplastes rubens. A: Unaspis yanonensis; B: Planococcus citri; C: Ceroplastes rubens. Genes outside the map are transcribed clockwise, whereas those inside the map are transcribed counterclockwise. The inside circles show the GC content and the GC skew. GC content and GC skew are plotted as the deviation from the average value of the entire sequence.

Fig. 2. Gene arrangements of Unaspis yanonensis, Planococcus citri and Ceroplastes rubens in comparison with Drosophila yakuba. A: Unaspis yanonensis; B: Planococcus citri; C: Ceroplastes rubens. Conserved gene arrangements are covered in grey areas.

Fig. 3. Reconstruction of mitochondrial gene rearrangement scenarios in the evolution of Unaspis yanonensis. The tRNA genes are represented by the amino acid abbreviations.

Fig. 4. Reconstruction of mitochondrial gene rearrangement scenarios in the evolution of Planococcus citri. The tRNA genes are represented by the amino acid abbreviations.

Fig. 5. Reconstruction of mitochondrial gene rearrangement scenarios in the evolution of Ceroplastes rubens. The tRNA genes are represented by the amino acid abbreviations.

Fig. 6. Comparison of the length for each PCG and rRNA gene in Unaspis yanonensis, Planococcus citri and Ceroplastes rubens.

Fig. 7. Relative synonymous codon usage (RSCU) of PCGs in Unaspis yanonensis, Planococcus citri and Ceroplastes rubens. A: Unaspis yanonensis; B: Planococcus citri; C: Ceroplastes rubens. Full codon families are indicated below the X-axis. 
Fig. 8. Average evolutionary rates of PCGs in Unaspis yanonensis, Planococcus citri and Ceroplastes rubens. The bar indicates each gene's Ka/Ks value.

Fig. 9. Secondary structures of tRNA genes in the mitogenome of Unaspis yanonensis. A: trnA (Alanine); B: trnN (Asparagine); C: trnD (Aspartic acid); D: trnR (Arginine); E: trnC (Cystine); F: trnQ (Glutamine); G: trnE (Glutamic acid); H: trnG (Glycine); I: trnH (Histidine); J: trnI (Isoleucine); K: trnL1(CUN) (Leucine); L: trnL2(UUR) (Leucine); M: trnK (Lysine); N: $\operatorname{trnM}$ (Methionine); O: trnF (Phenylalanine); P: trnP (Proline); Q: $\operatorname{trnS} 1(\mathrm{AGN})($ Serine); R: $\operatorname{trnS} 2(\mathrm{UCN})$ (Serine); S: trnT (Threonine); T: trnW (Tryptophan); U: trn $\mathrm{Y}$ (Tyrosine); V: trnV (Valine). The tRNA genes are labelled with their corresponding amino acids.

Fig. 10. Secondary structures of tRNA genes in the mitogenome of Planococcus citri. A: $\operatorname{trn} A$ (Alanine); B: trnN (Asparagine); C: trnD (Aspartic acid); D: trnR (Arginine); E: trnC (Cystine); F: trnQ (Glutamine); G: trnE (Glutamic acid); H: trnG (Glycine); I: trnH (Histidine); J: trnI (Isoleucine); K: trnL1(CUN) (Leucine); L: trnL2(UUR) (Leucine); M: trnK (Lysine); N: $\operatorname{trnM}$ (Methionine); O: trnF (Phenylalanine); P: trnP (Proline); Q: $\operatorname{trnS} 1(\mathrm{AGN})$ (Serine); R: trnS2(UCN) (Serine); S: trnT (Threonine); T: trnW (Tryptophan); U: trnY (Tyrosine). The tRNA genes are labelled with their corresponding amino acids.

Fig. 11. Secondary structures of tRNA genes in the mitogenome of Ceroplastes rubens. A: $\operatorname{trn} \mathrm{A}$ (Alanine); B: trnN (Asparagine); C: trnD (Aspartic acid); D: trnE (Glutamic acid); E: trnQ (Glutamine); F: trnG (Glycine); G: trnH (Histidine); H: trnI (Isoleucine); I: trnL2(UUR) (Leucine); J: trnK (Lysine); K: trnM (Methionine); L: trnF (Phenylalanine); M: trnP (Proline); N: trnS1(AGN) (Serine); O: $\operatorname{trn} \mathrm{T}$ (Threonine); P: trnW (Tryptophan); Q: trnY (Tyrosine). The tRNA genes are labelled with their corresponding amino acids. 
415 Fig. 12. Predicted structural elements in the control regions of Unaspis yanonensis, 416 Planococcus citri and Ceroplastes rubens. Tandem repeat units are indicated by orange boxes.

417 Poly-[TA]n stretch is indicated with purple ellipse. Stem-loop structure is indicated by its shape 418 and base pairs.

419

420 Fig. 13. Phylogenetic relationships within Coccoidea inferred by Bayesian inference (left)

421 and maximum likelihood analysis (right). Numbers at the nodes are posterior probabilities (left)

422 and bootstrap values (right). The family names are listed after the species. 


\section{Figure 1}

Mitochondrial maps of Unaspis yanonensis, Planococcus citri and Ceroplastes rubens.

A: Unaspis yanonensis; B: Planococcus citri; C: Ceroplastes rubens. Genes outside the map are transcribed clockwise, whereas those inside the map are transcribed counterclockwise. The inside circles show the GC content and the GC skew. GC content and GC skew are plotted as the deviation from the average value of the entire sequence. 


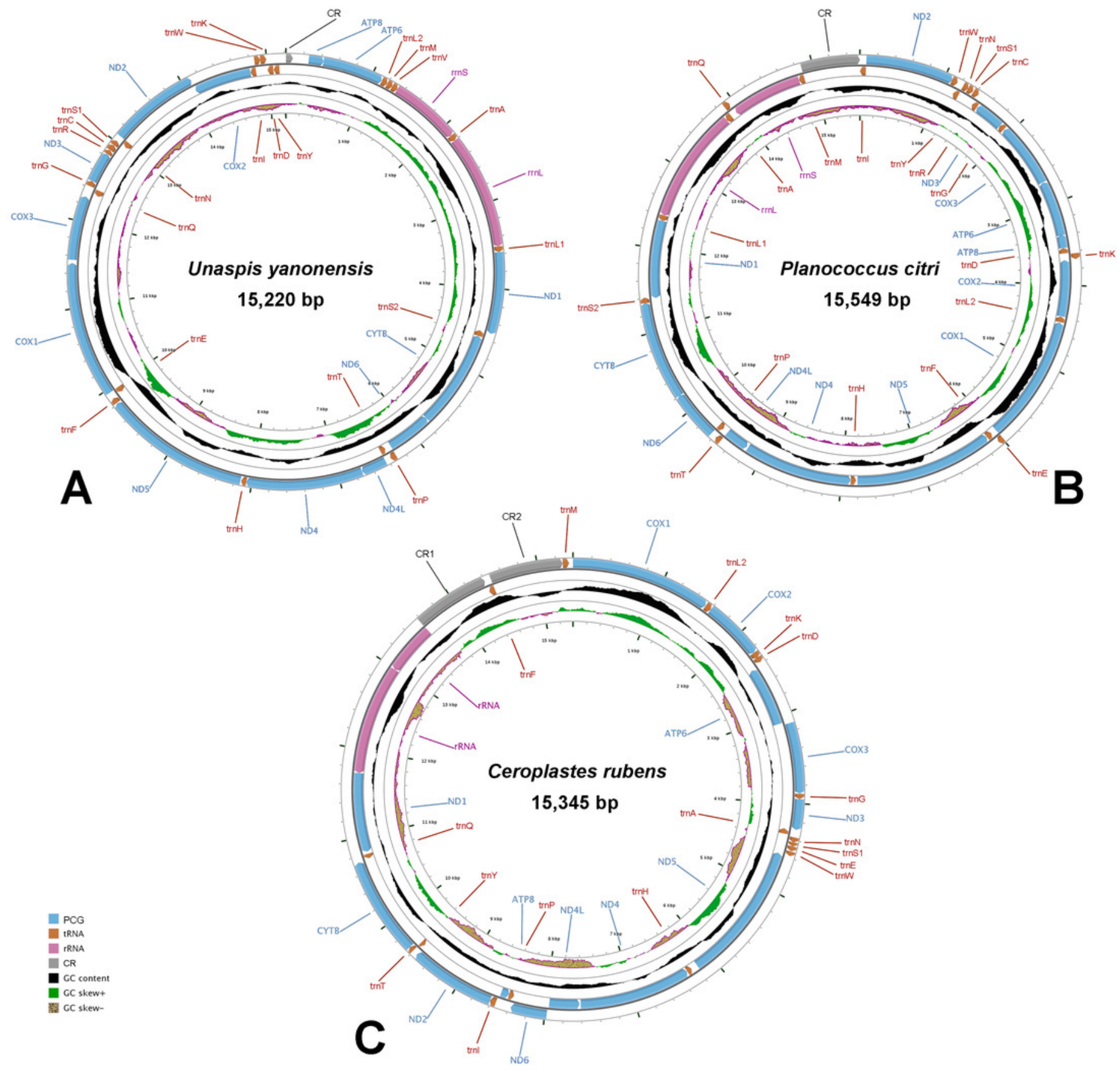


Figure 2

Gene arrangements of Unaspis yanonensis, Planococcus citri and Ceroplastes rubens in comparison with Drosophila yakuba.

A: Unaspis yanonensis; B: Planococcus citri; C: Ceroplastes rubens. Conserved gene arrangements are covered in grey areas.

\section{A}

Drosophila yakuba mitochondrial genome $16,019 \mathrm{bp}$

Unaspis yanonensis mitochondrial genome

15,220 bp

B

Drosophila yakuba mitochondrial genome 16,019 bp

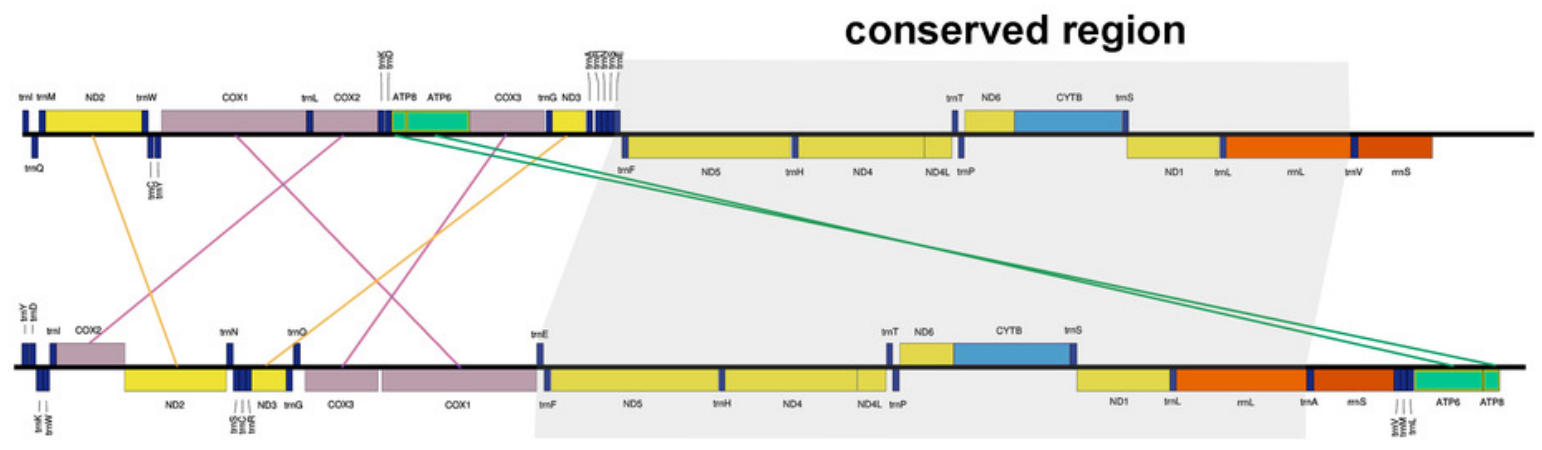

conserved region

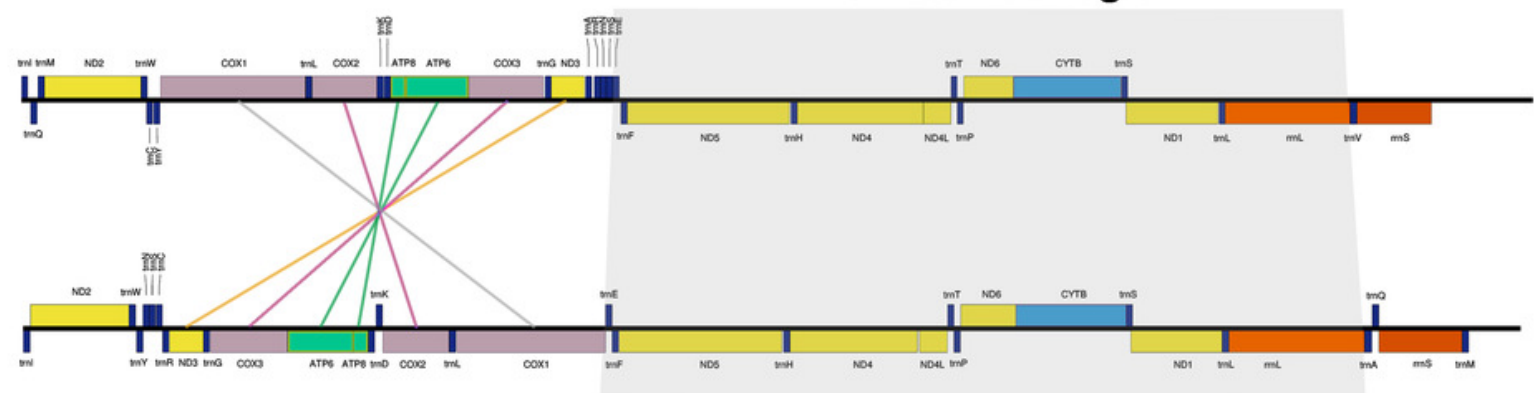

\section{conserved region}

C

Drosophila yakuba mitochondrial genome $16,019 \mathrm{bp}$

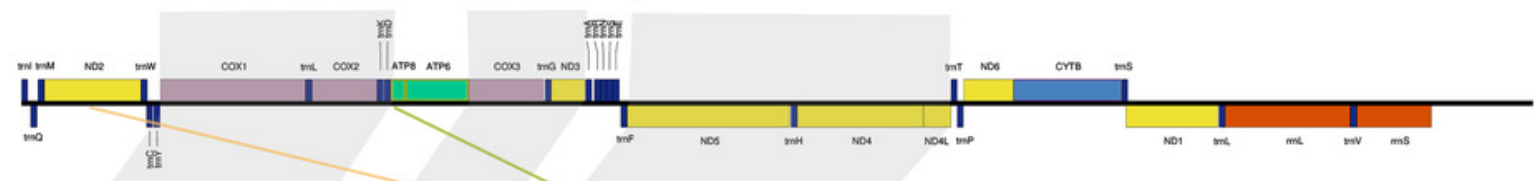

Ceroplastes rubens mitochondrial genome $15,387 \mathrm{bp}$

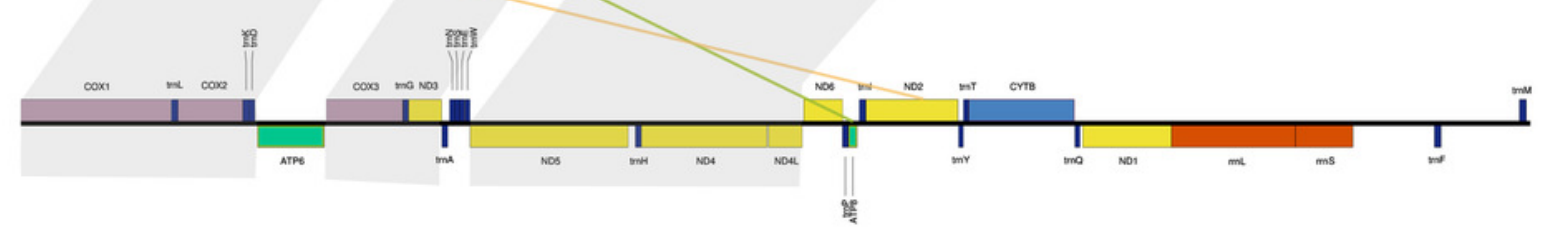


Figure 3

Reconstruction of mitochondrial gene rearrangement scenarios in the evolution of Unaspis yanonensis.

The tRNA genes are represented by the amino acid abbreviations. 
- family diagram for Drosophila yakuba

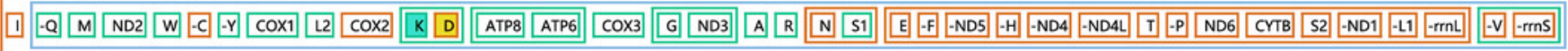
- family diagram for Unaspis yanonensis

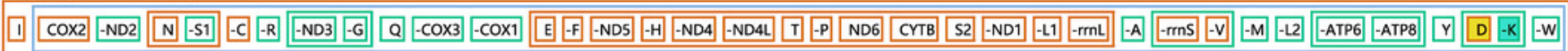
- scenario:

- transposition

$-v--m s$

$-i m s$ - $-v$

- reverse transposition

K D

$D-K$

0 reversal

s1

$-51$

- prime scenario(s)

- alternative scenario 1 of 2

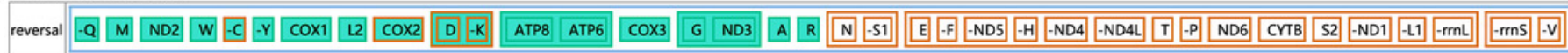

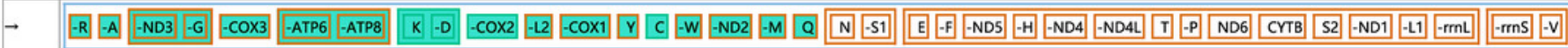

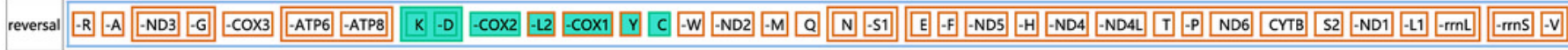

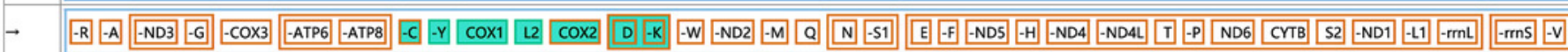

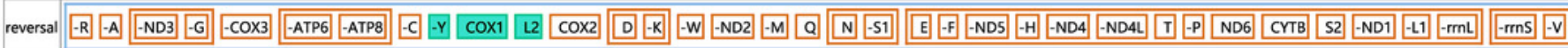

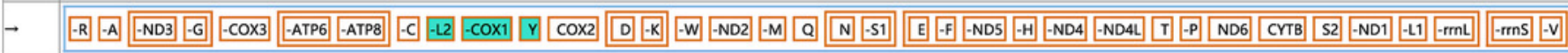

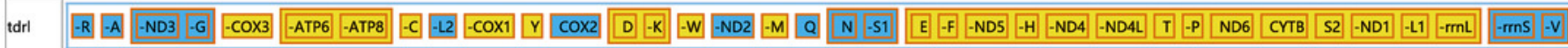

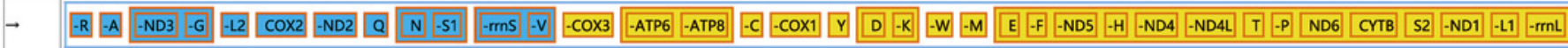

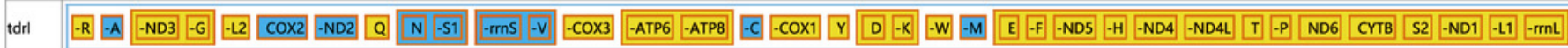

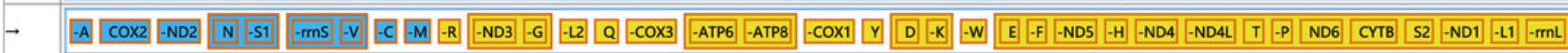

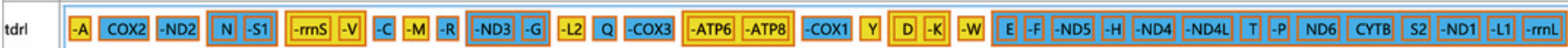

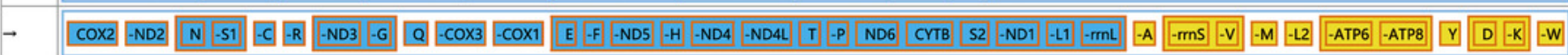

- alternative scenario 2 of 2

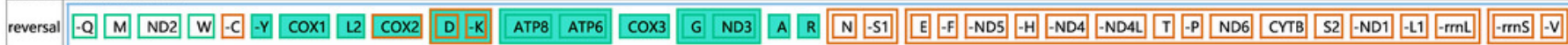

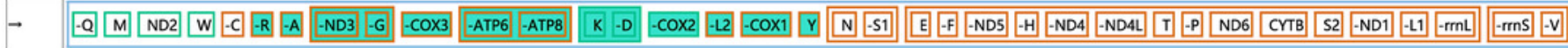

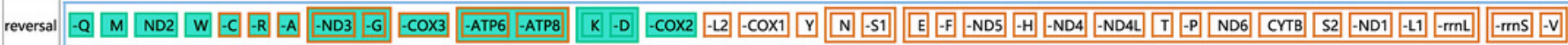

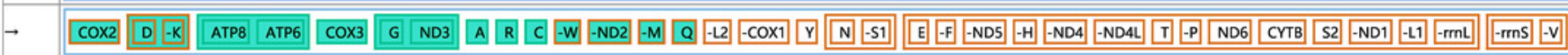

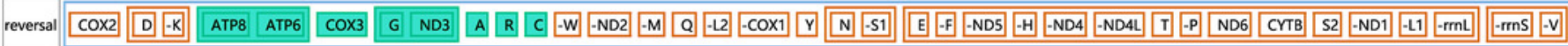

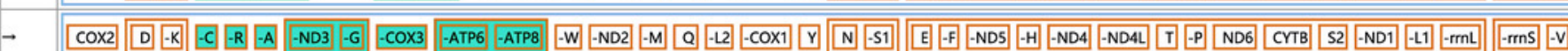

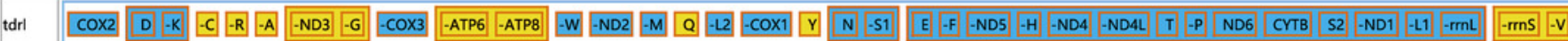

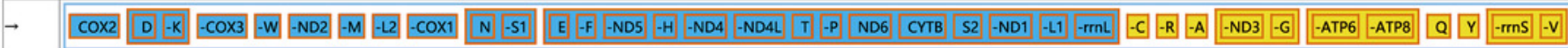

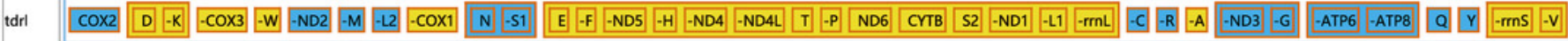

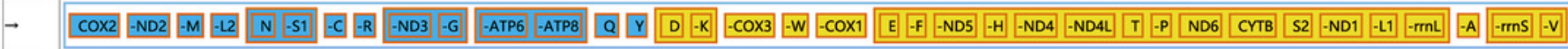

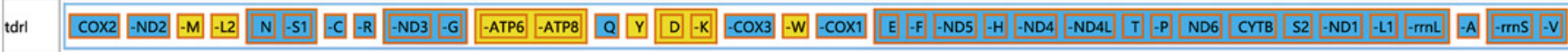

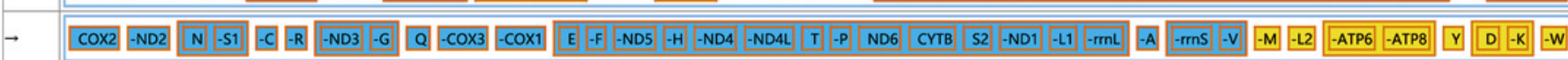


Figure 4

\section{Reconstruction of mitochondrial gene rearrangement scenarios in the evolution of Planococcus citri.}

The tRNA genes are represented by the amino acid abbreviations.

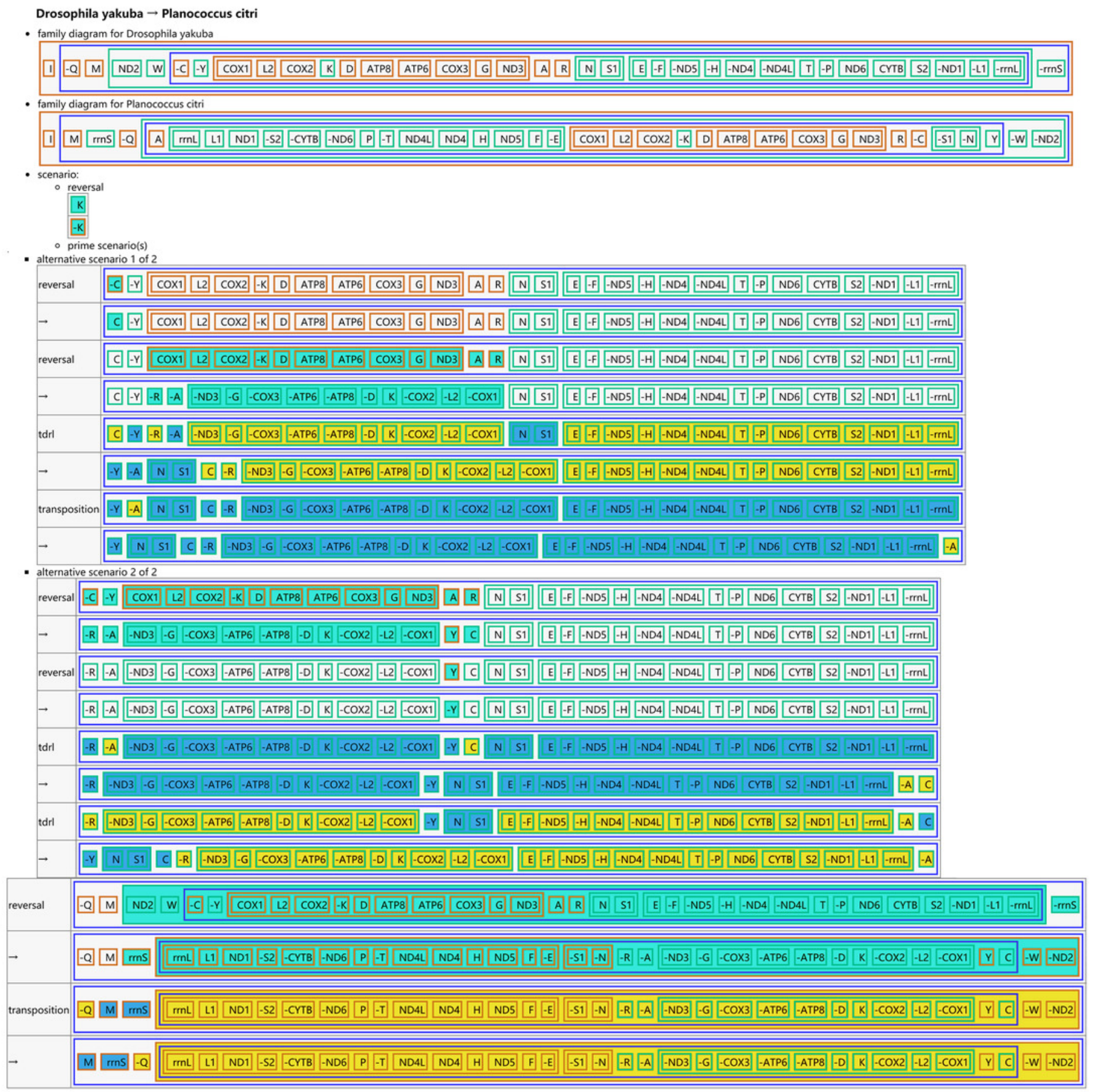




\section{Figure 5}

Reconstruction of mitochondrial gene rearrangement scenarios in the evolution of Ceroplastes rubens.

The tRNA genes are represented by the amino acid abbreviations.

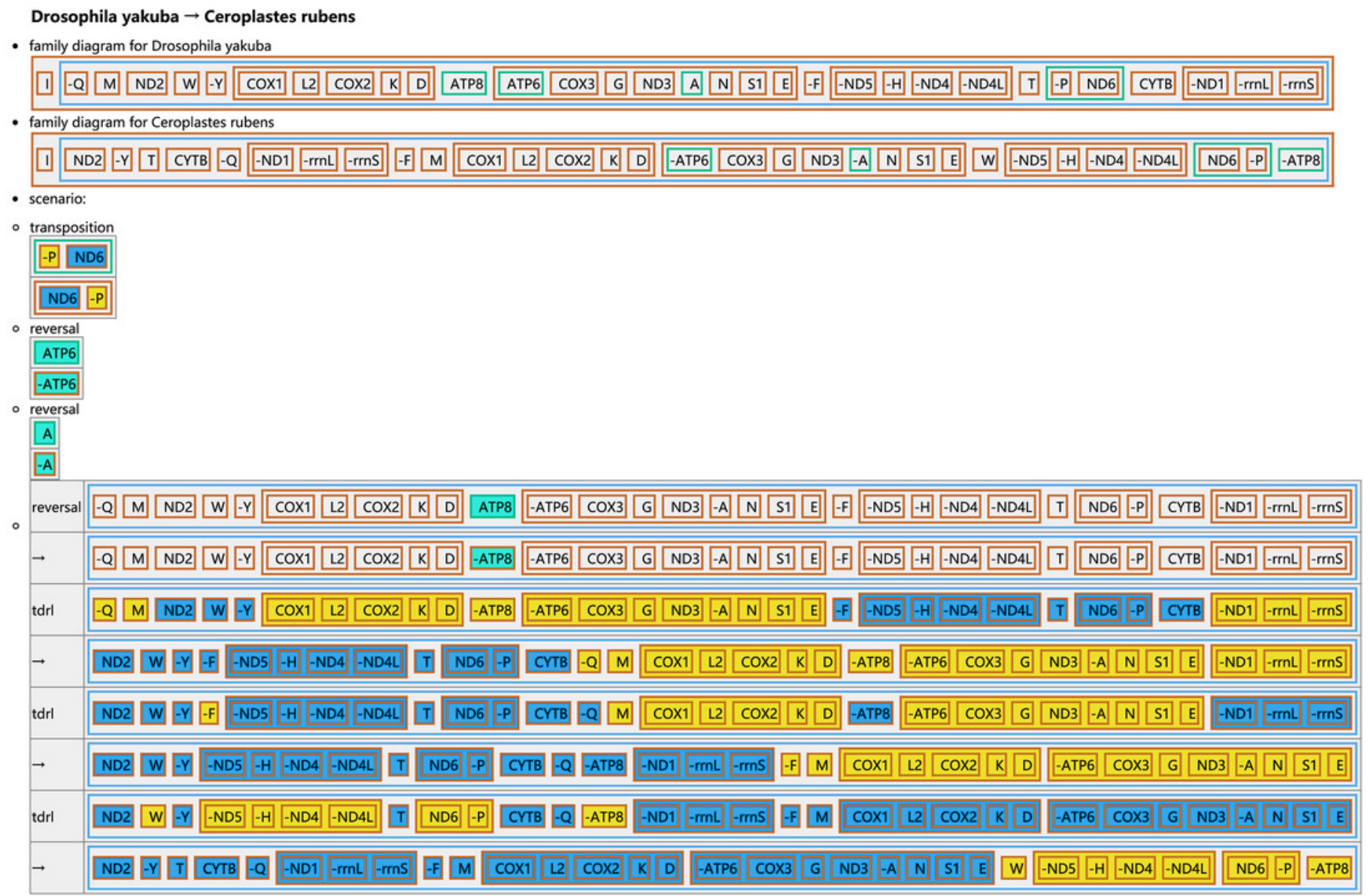


Figure 6

Comparison of the length for each PCG and rRNA gene in Unaspis yanonensis, Planococcus citri and Ceroplastes rubens.

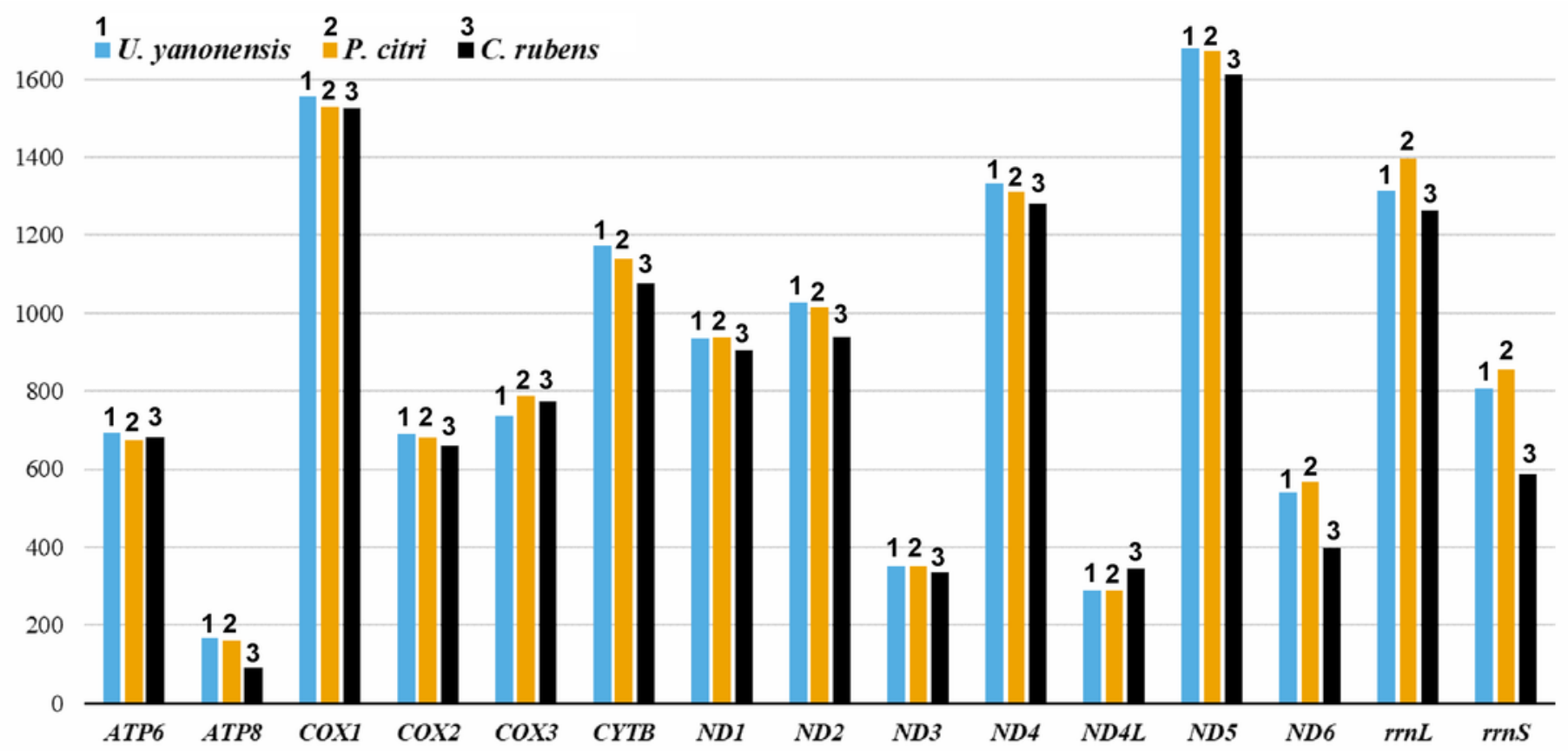


Figure 7

Relative synonymous codon usage (RSCU) of PCGs in Unaspis yanonensis, Planococcus citri and Ceroplastes rubens.

A: Unaspis yanonensis; B: Planococcus citri; C: Ceroplastes rubens. Full codon families are indicated below the X-axis.
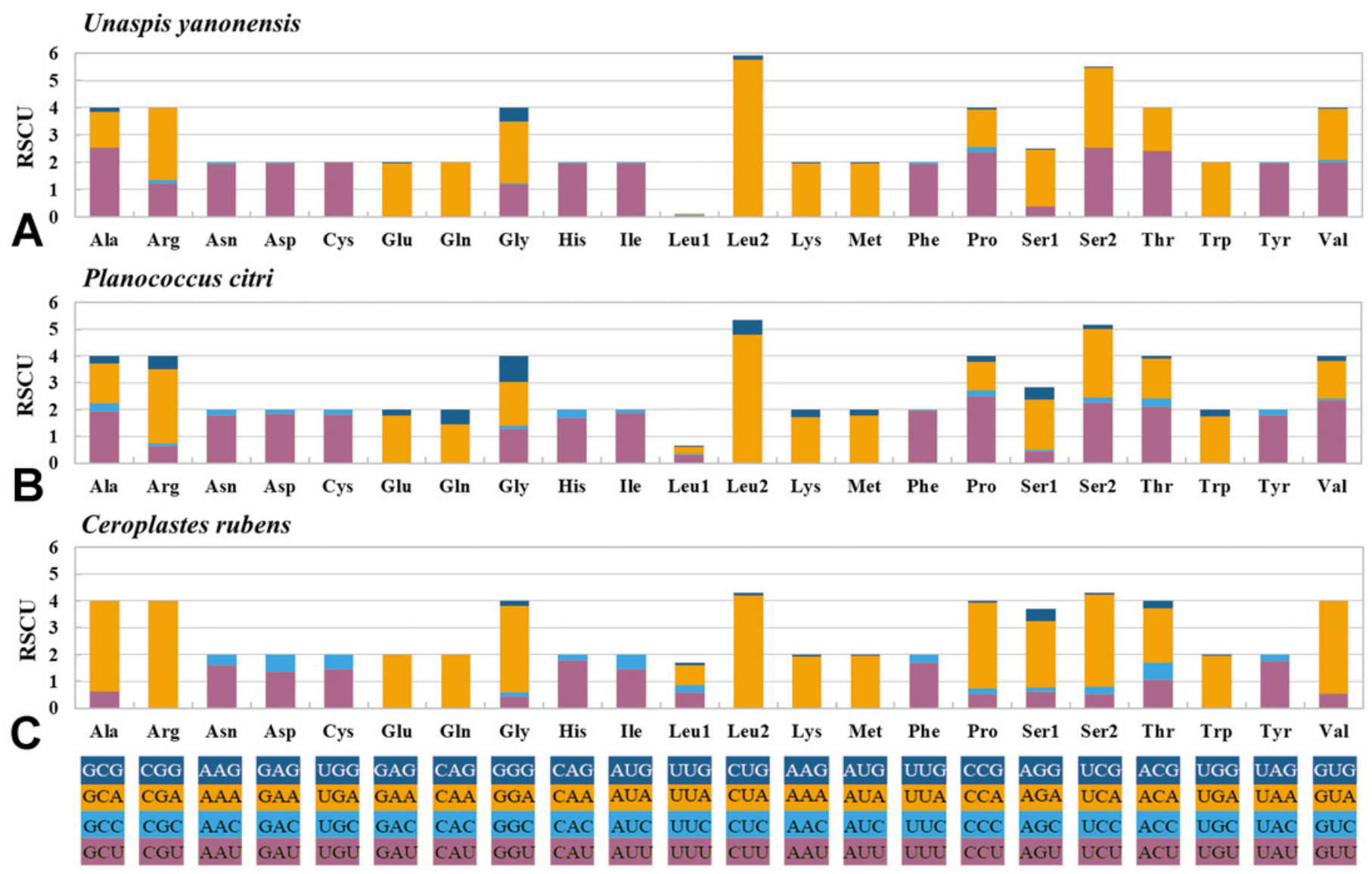
Figure 8

Average evolutionary rates of PCGs in Unaspis yanonensis, Planococcus citri and Ceroplastes rubens.

The bar indicates each gene's Ka/Ks value.

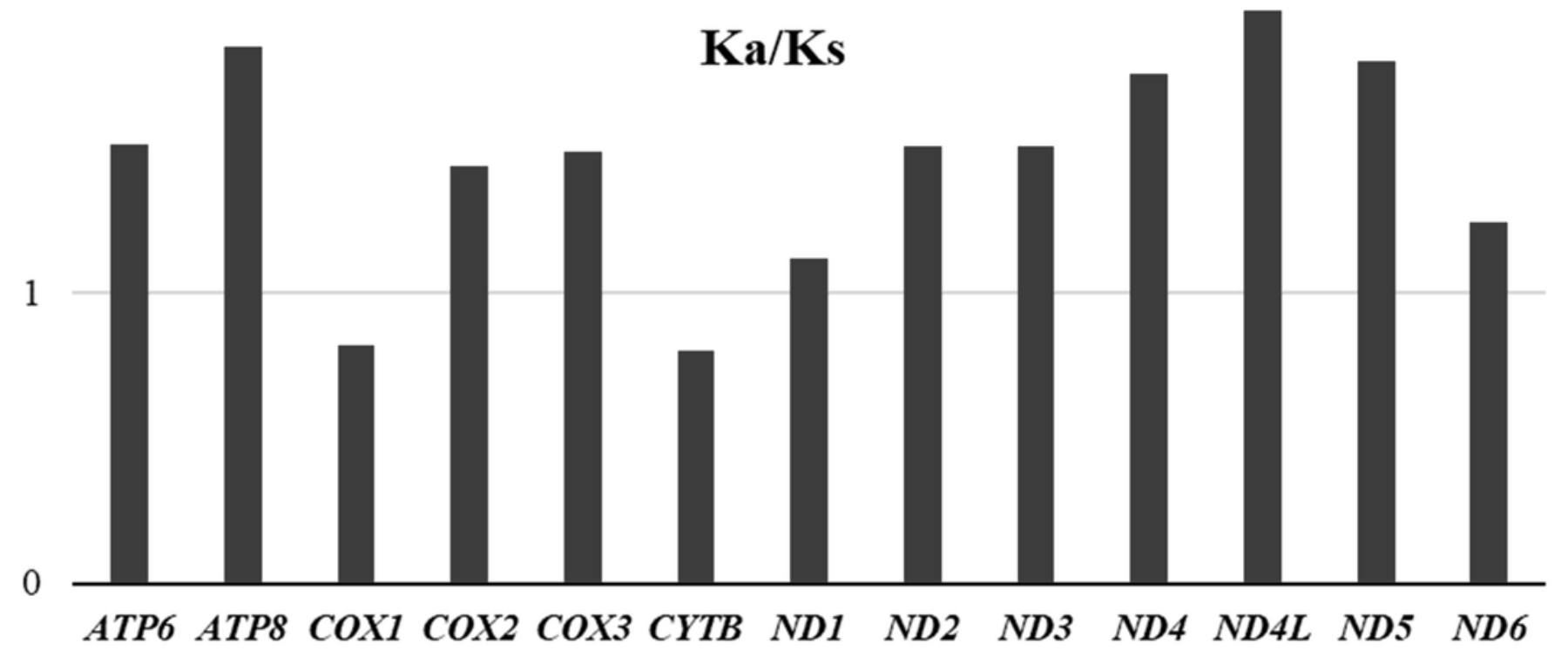




\section{Figure 9}

Secondary structures of tRNA genes in the mitogenome of Unaspis yanonensis.

A: $\operatorname{trnA}$ (Alanine); B: trnN (Asparagine); C: trnD (Aspartic acid); D: trnR (Arginine); E: trnC (Cystine); F: trnQ (Glutamine); G: trnE (Glutamic acid); H: trnG (Glycine); I: trnH (Histidine); J:

trnl (Isoleucine); K: trnL1(CUN) (Leucine); L: trnL2(UUR) (Leucine); M: trnK (Lysine); N: trnM (Methionine); O: trnF (Phenylalanine); P: trnP (Proline); Q: trnS1(AGN) (Serine); R: trnS2(UCN) (Serine); S: trnT (Threonine); T: trnW (Tryptophan); U: trnY (Tyrosine); V: trnV (Valine). The tRNA genes are labelled with their corresponding amino acids. 

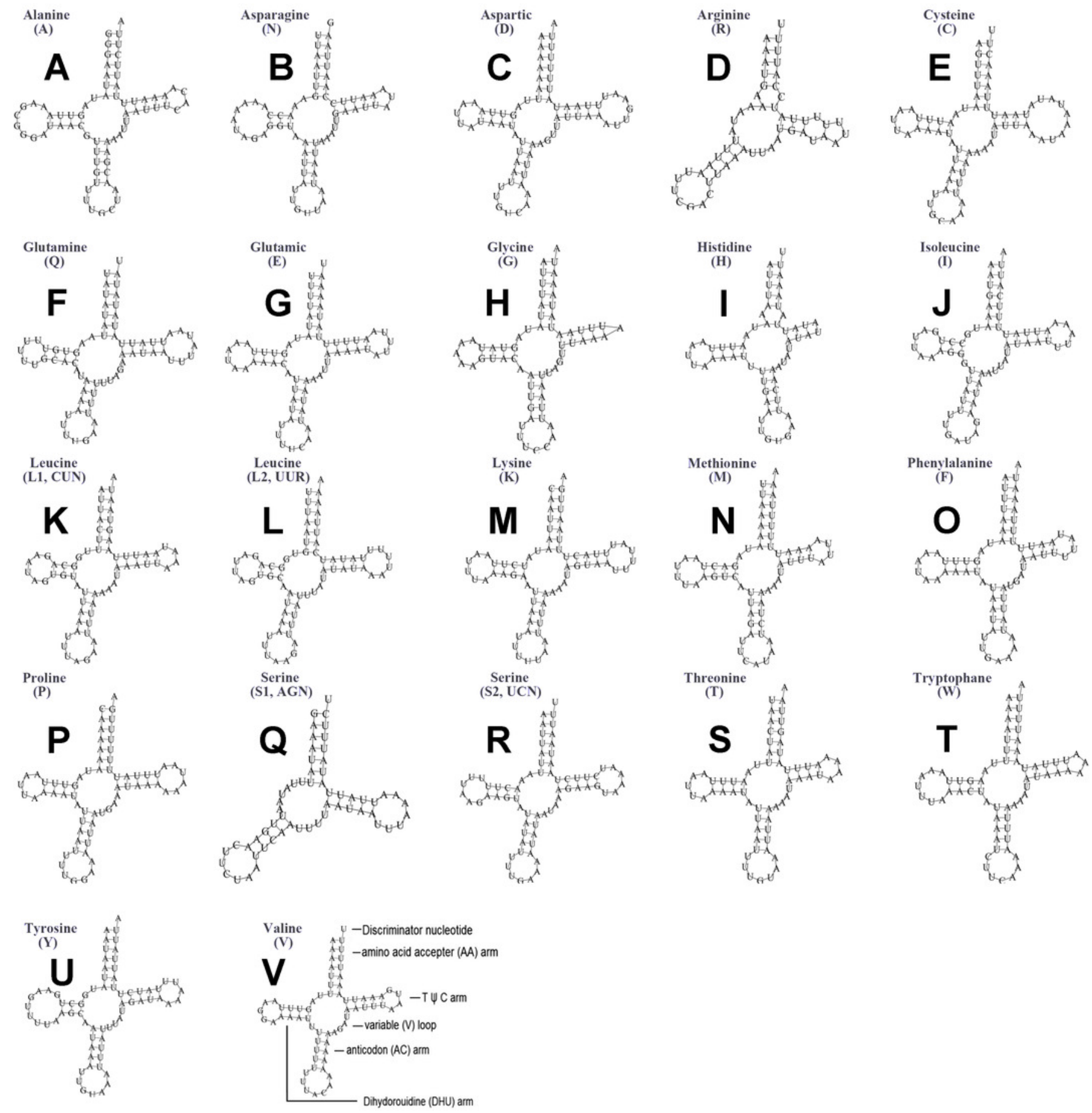


\section{Figure 10}

Secondary structures of tRNA genes in the mitogenome of Planococcus citri.

A: $\operatorname{trn} A$ (Alanine); B: $\operatorname{trnN}$ (Asparagine); C: $\operatorname{trnD}$ (Aspartic acid); D: $\operatorname{trnR}$ (Arginine); E: $\operatorname{trnC}$ (Cystine); F: trnQ (Glutamine); G: trnE (Glutamic acid); H: trnG (Glycine); I: trnH (Histidine); J:

trnl (Isoleucine); K: trnL1(CUN) (Leucine); L: trnL2(UUR) (Leucine); M: trnK (Lysine); N: trnM (Methionine); O: trnF (Phenylalanine); P: trnP (Proline); Q: trnS1(AGN) (Serine); R: trnS2(UCN) (Serine); S: trnT (Threonine); T: trnW (Tryptophan); U: trnY (Tyrosine). The tRNA genes are labelled with their corresponding amino acids. 

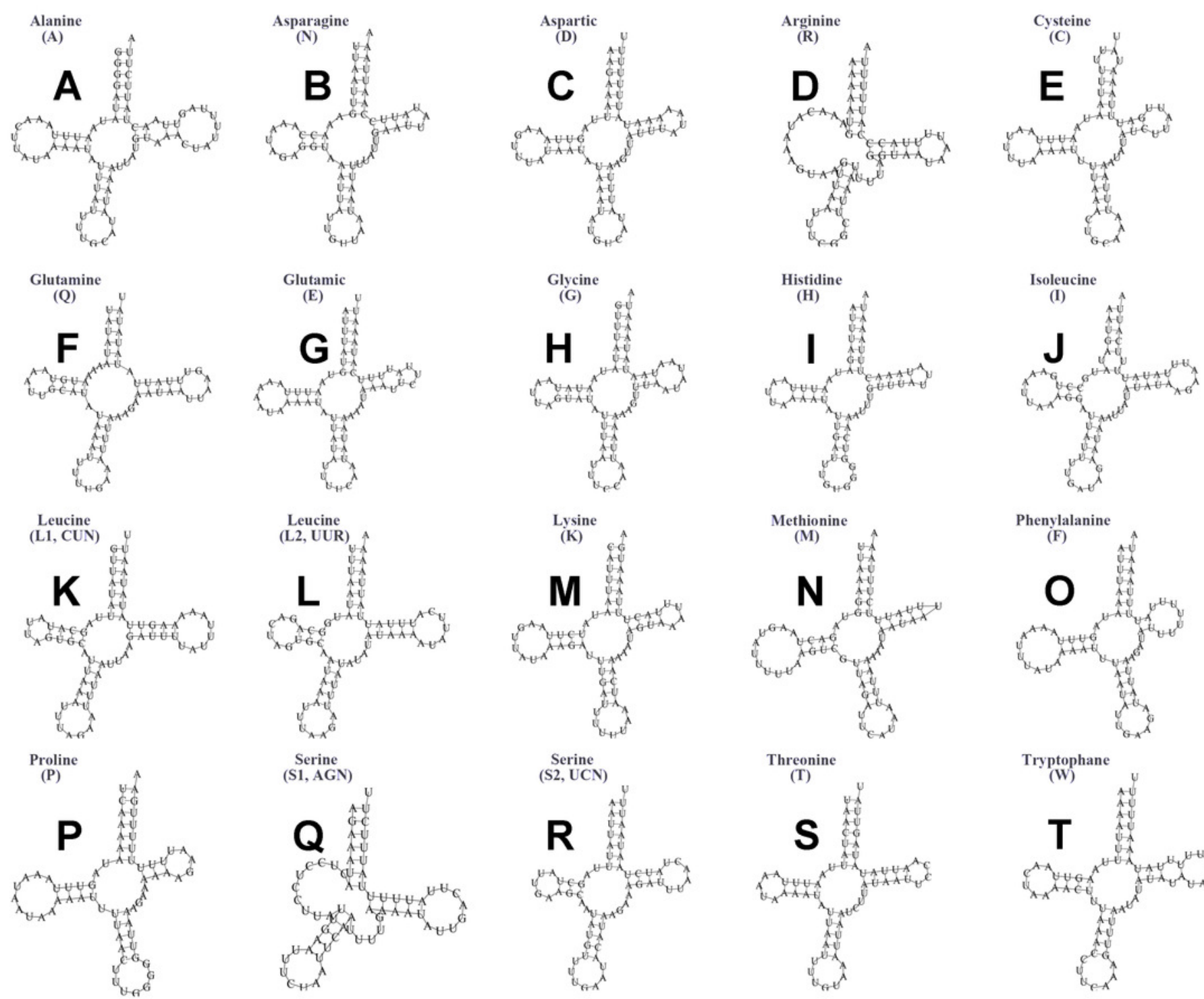

Serine
(S1, AGN)
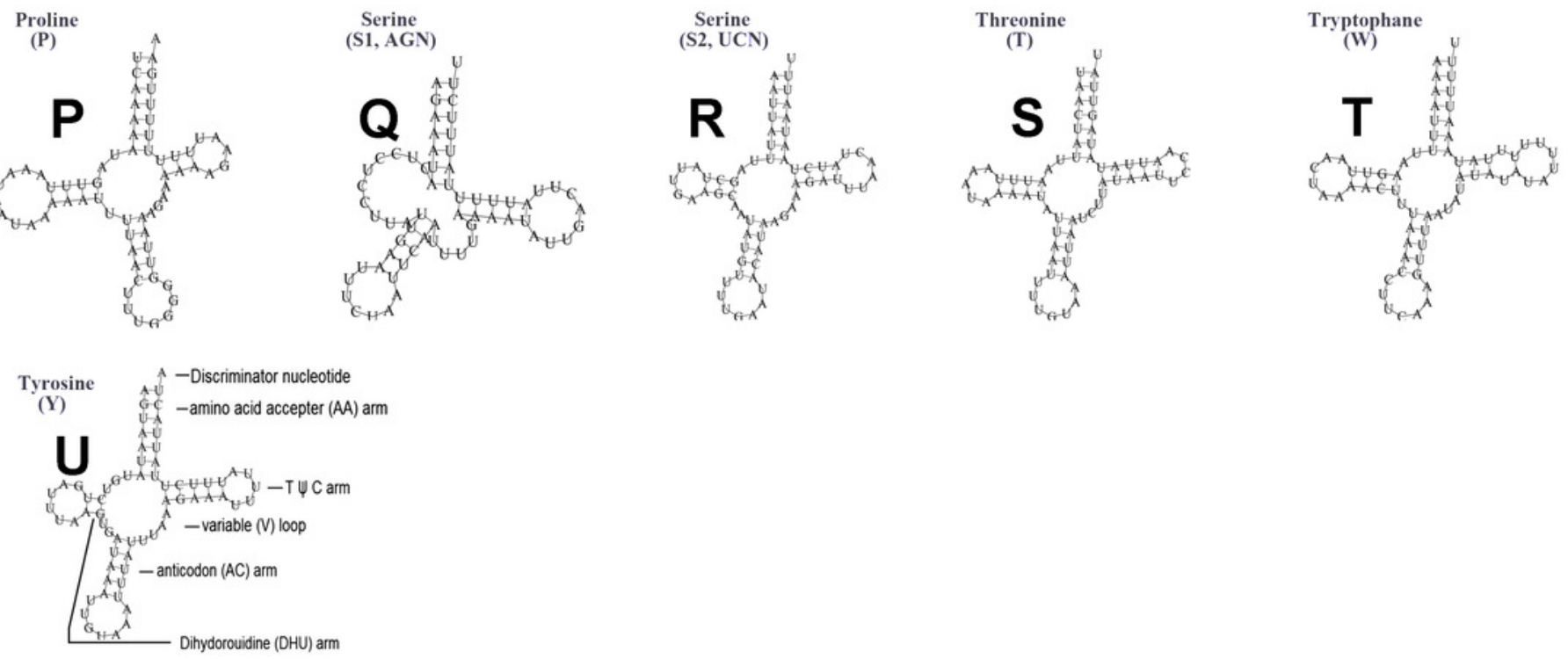


\section{Figure 11}

Secondary structures of tRNA genes in the mitogenome of Ceroplastes rubens.

A: $\operatorname{trn} A$ (Alanine); B: trnN (Asparagine); C: trnD (Aspartic acid); D: trnE (Glutamic acid); E: trnQ (Glutamine); F: trnG (Glycine); G: trnH (Histidine); H: trnl (Isoleucine); I: trnL2(UUR) (Leucine); J: trnK (Lysine); K: trnM (Methionine); L: trnF (Phenylalanine); M: trnP (Proline); N: trnS1(AGN) (Serine); O: trnT (Threonine); P: trnW (Tryptophan); Q: trnY (Tyrosine). The tRNA genes are labelled with their corresponding amino acids. 


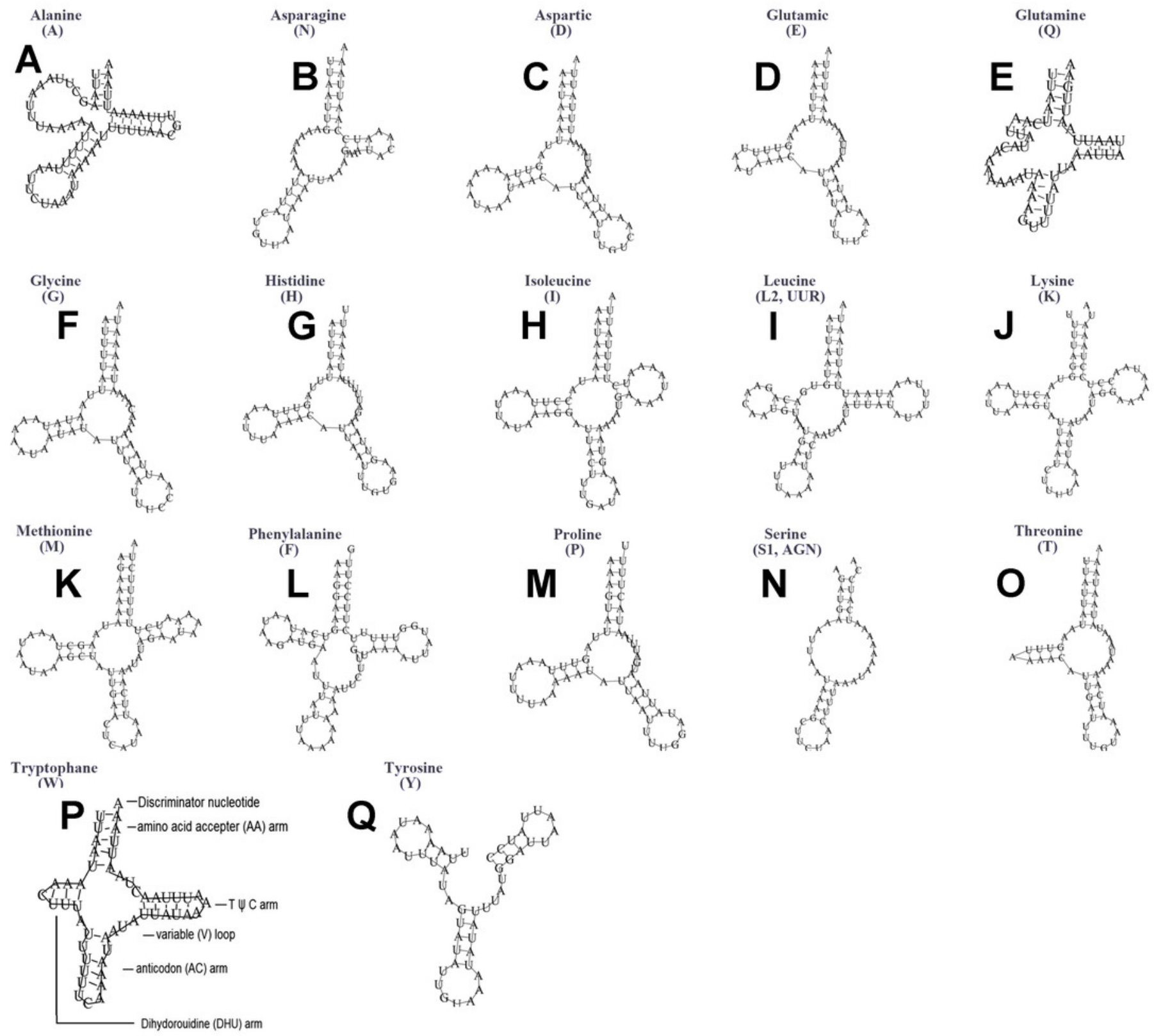




\section{Figure 12}

Predicted structural elements in the control regions of Unaspis yanonensis, Planococcus citri and Ceroplastes rubens.

Tandem repeat units are indicated by orange boxes. Poly-[TA]n stretch is indicated with purple ellipse. Stem-loop structure is indicated by its shape and base pairs. 


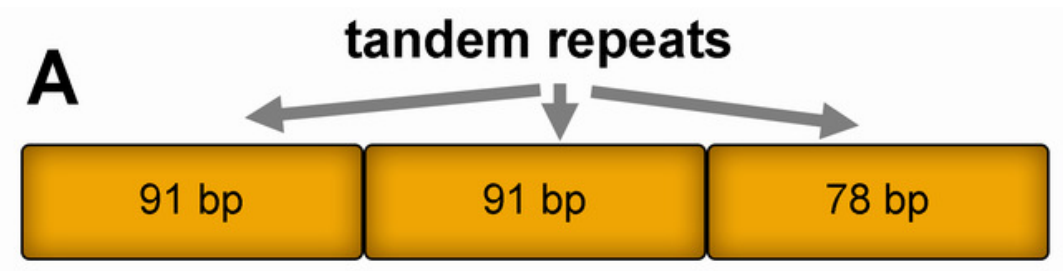

Unaspis yanonensis

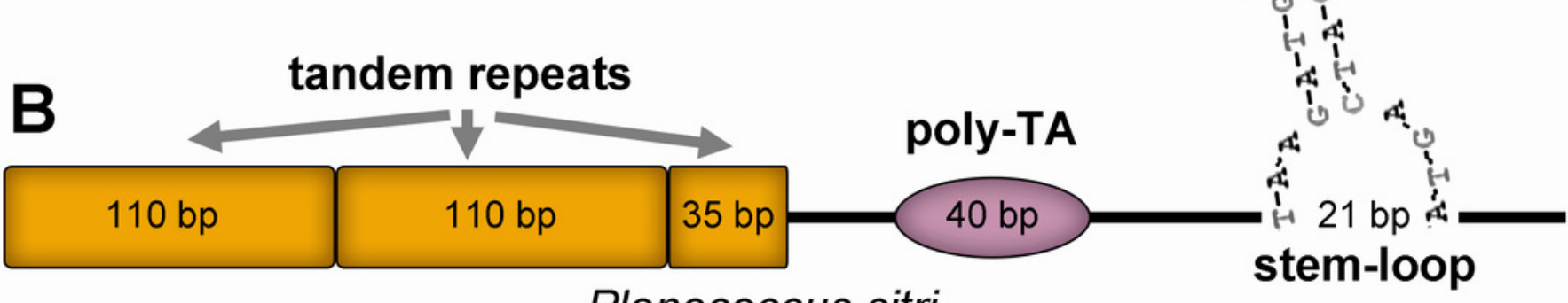

Planococcus citri

C

$33 \mathrm{bp} 33 \mathrm{bp} 33 \mathrm{bp}$

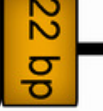

Ceroplastes rubens CR1
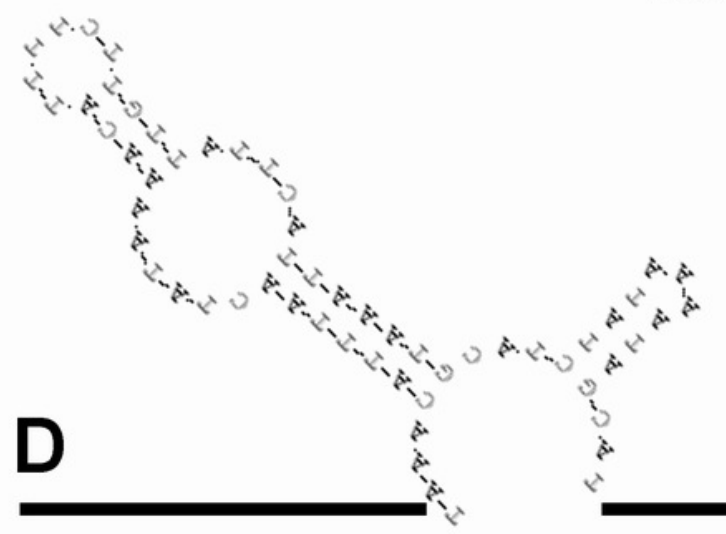

Ceroplastes rubens CR2 
Figure 13

Phylogenetic relationships within Coccoidea inferred by Bayesian inference (left) and maximum likelihood analysis (right).

Numbers at the nodes are posterior probabilities (left) and bootstrap values (right). The family names are listed after the species.

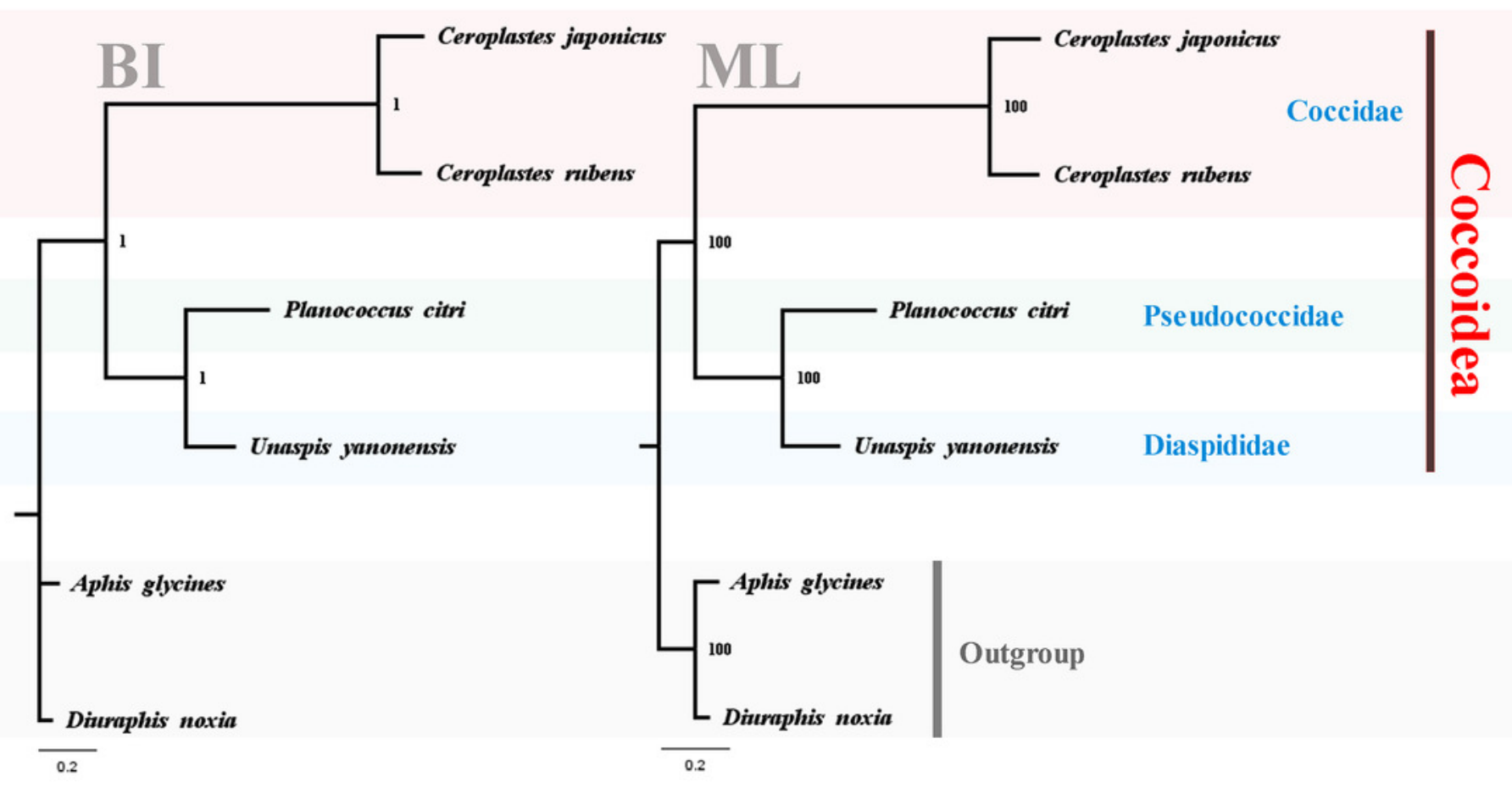




\section{Table 1 (on next page)}

Species of Hemiptera used in this study. 
1 Table 1:

2 Species of Hemiptera used in this study. Superfamily Family Species Accession number

Coccoidea

Coccidae

Ceroplastes japonicus

MK847519

Ceroplastes rubens

MT677923

Diaspididae

Unaspis yanonensis

MT611525

Pseudococcidae Planococcus citri

Aphidoidea

Aphididae

Aphis glycines

MT611526

Diuraphis noxia

MK111111

KF636758

3

4 
Table 2 (on next page)

Mitochondrial genome structure of Unaspis yanonensis. 
1 Table 2:

2 Mitochondrial genome structure of Unaspis yanonensis.

\begin{tabular}{|c|c|c|c|c|c|c|}
\hline Gene & Position (bp) & Size (bp) & Direction & $\begin{array}{l}\text { Intergenic } \\
\text { nucleotides }\end{array}$ & $\begin{array}{c}\text { Anti- or } \\
\text { start/stop } \\
\text { codons }\end{array}$ & $\mathbf{A}+\mathbf{T} \%$ \\
\hline Control region & $1-78$ & 260 & + & 78 & - & 81.9 \\
\hline ATP8 & $261-428$ & 168 & + & 0 & ATT/TAA & 93.5 \\
\hline ATP6 & $429-1121$ & 693 & + & 0 & ATT/TAA & 86.0 \\
\hline $\operatorname{trnL2}(U U R)$ & $1127-1193$ & 67 & + & 5 & TAA & 85.1 \\
\hline trnMet $(M)$ & $1196-1260$ & 65 & + & 2 & CAT & 89.2 \\
\hline trnVal $(V)$ & $1261-1326$ & 66 & + & 0 & $\mathrm{TAC}$ & 90.9 \\
\hline$r r n S$ & $1327-2133$ & 807 & + & 0 & - & 90.6 \\
\hline trnAla $(A)$ & 2134-2202 & 69 & + & 0 & TGC & 72.5 \\
\hline$r r n L$ & $2203-3516$ & 1314 & + & 0 & - & 89.6 \\
\hline trnLeul (CUN) & $3517-3581$ & 65 & + & 0 & TAG & 86.2 \\
\hline nad1 & $3582-4517$ & 936 & + & 0 & ATT/TAA & 84.5 \\
\hline trnSer2 (UCN) & $4516-4584$ & 69 & - & -2 & TGA & 88.4 \\
\hline CYTB & $4587-5759$ & 1173 & - & 2 & ATA/TAA & 81.8 \\
\hline ND6 & $5760-6300$ & 541 & - & 0 & ATG/T- & 93.0 \\
\hline trnPro $(P)$ & $6306-6373$ & 68 & + & 5 & TGG & 91.2 \\
\hline trnThr (T) & $6374-6437$ & 64 & - & 0 & TGT & 95.3 \\
\hline ND4L & $6441-6728$ & 288 & + & 3 & ATT/TAA & 89.9 \\
\hline ND4 & $6731-8062$ & 1332 & + & 2 & ATT/TAA & 87.8 \\
\hline trnHis $(H)$ & $8062-8121$ & 60 & + & -1 & GTG & 93.3 \\
\hline ND5 & $8131-9810$ & 1680 & + & 9 & ATA/TAA & 88.2 \\
\hline trnPhe $(F)$ & 9818-9882 & 65 & + & 7 & GAA & 95.4 \\
\hline $\operatorname{trn} G l u(E)$ & 9890-9957 & 68 & - & 7 & TTC & 95.6 \\
\hline$C O X 1$ & $9959-11515$ & 1557 & + & 1 & TTG/TAA & 78.4 \\
\hline COX3 & $11554-12288$ & 735 & + & 38 & ATT/TAA & 82.3 \\
\hline $\operatorname{trn} G \ln (Q)$ & $12339-12407$ & 69 & - & 50 & TTG & 89.9 \\
\hline $\operatorname{trn} G l y(G)$ & $12417-12479$ & 63 & + & 9 & TCC & 88.9 \\
\hline ND3 & $12480-12830$ & 351 & + & 0 & ATT/TAA & 88.3 \\
\hline $\operatorname{trnArg}(R)$ & $12831-12883$ & 53 & + & 0 & TCG & 86.8 \\
\hline $\operatorname{trn} C y s(C)$ & $12885-12954$ & 70 & + & 1 & GCA & 94.3 \\
\hline trnSerl $(A G N)$ & $12956-13014$ & 59 & + & 1 & GCT & 89.8 \\
\hline trnAsn (N) & $13013-13080$ & 68 & - & -2 & GTT & 83.8 \\
\hline ND2 & $13082-14107$ & 1026 & + & 1 & ATT/TAA & 92.1 \\
\hline$C O X 2$ & $14104-14793$ & 690 & - & -4 & ATT/TAA & 83.6 \\
\hline trnIle (I) & $14795-14861$ & 67 & - & 1 & GAT & 83.6 \\
\hline $\operatorname{trnTrp}(W)$ & $14862-14928$ & 67 & + & 0 & TCA & 94.0 \\
\hline $\operatorname{trnLys}(K)$ & 14929-14997 & 69 & + & 0 & CTT & 91.3 \\
\hline $\operatorname{trnAsp}(D)$ & $15001-15069$ & 69 & - & 3 & GTC & 92.8 \\
\hline $\operatorname{trnTyr}(Y)$ & $15074-15142$ & 69 & - & 4 & GTA & 85.5 \\
\hline
\end{tabular}


Table 3 (on next page)

Mitochondrial genome structure of Planococcus citri. 
1 Table 3:

2 Mitochondrial genome structure of Planococcus citri.

\begin{tabular}{|c|c|c|c|c|c|c|}
\hline Gene & Position (bp) & Size (bp) & Direction & $\begin{array}{l}\text { Intergenic } \\
\text { nucleotides }\end{array}$ & $\begin{array}{c}\text { Anti- or } \\
\text { start/stop } \\
\text { codons }\end{array}$ & $\mathrm{A}+\mathrm{T} \%$ \\
\hline trnIle (I) & $1-70$ & 70 & - & 0 & GAT & 84.3 \\
\hline ND2 & $76-1089$ & 1014 & + & 5 & ATT/TAA & 87.4 \\
\hline $\operatorname{trnTrp}(W)$ & $1088-1156$ & 69 & + & -2 & TCA & 89.9 \\
\hline $\operatorname{trnTyr}(Y)$ & $1167-1232$ & 66 & - & 10 & GTA & 84.8 \\
\hline $\operatorname{trn} A s n(N)$ & $1232-1295$ & 64 & + & -1 & GTT & 84.4 \\
\hline trnSerl (AGN) & $1295-1359$ & 65 & + & -1 & GCT & 80.0 \\
\hline $\operatorname{trnCys}(C)$ & $1368-1432$ & 65 & + & 8 & GCA & 92.3 \\
\hline $\operatorname{trnArg}(R)$ & $1434-1497$ & 64 & - & 1 & TCG & 79.7 \\
\hline ND3 & $1504-1854$ & 351 & - & 6 & ATT/TAA & 84.3 \\
\hline $\operatorname{trn} G l y(G)$ & $1855-1918$ & 64 & - & 0 & TCC & 92.2 \\
\hline COX3 & $1928-2716$ & 789 & - & 9 & ATG/TAA & 76.6 \\
\hline ATP6 & $2721-3395$ & 675 & - & 4 & ATG/TAA & 80.1 \\
\hline ATP8 & $3389-3550$ & 162 & - & -7 & ATT/TAA & 85.8 \\
\hline $\operatorname{trnAsp}(D)$ & $3551-3616$ & 66 & - & 0 & GTC & 90.9 \\
\hline $\operatorname{trnLys}(K)$ & $3629-3695$ & 67 & + & 12 & CTT & 86.6 \\
\hline COX2 & $3700-4380$ & 681 & - & 4 & ATT/TAA & 78.6 \\
\hline trnLeu2 (UUR) & $4384-4451$ & 68 & - & 3 & TAA & 85.3 \\
\hline COX1 & $4460-5989$ & 1530 & - & 8 & ATA/TAA & 74.4 \\
\hline $\operatorname{trn} G l u(E)$ & $5991-6057$ & 67 & + & 1 & TTC & 94.0 \\
\hline trnPhe $(F)$ & $6057-6124$ & 68 & - & -1 & GAA & 94.1 \\
\hline ND5 & $6130-7803$ & 1674 & - & 5 & ATT/TAA & 84.3 \\
\hline trnHis $(H)$ & $7822-7886$ & 65 & - & 18 & GTG & 84.6 \\
\hline ND4 & 7889-9199 & 1311 & - & 2 & ATA/TAA & 83.5 \\
\hline$N D 4 L$ & $9220-9507$ & 288 & - & 20 & ATT/TAA & 86.8 \\
\hline $\operatorname{trnThr}(T)$ & $9510-9575$ & 66 & + & 2 & TGT & 90.9 \\
\hline trnPro $(P)$ & $9575-9641$ & 67 & - & -1 & TGG & 83.6 \\
\hline ND6 & $9645-10212$ & 568 & + & 3 & ATG/T- & 86.6 \\
\hline CYTB & $10210-11349$ & 1140 & + & -3 & ATT/TAA & 77.3 \\
\hline trnSer2 (UCN) & $11348-11412$ & 65 & + & -2 & TGA & 81.5 \\
\hline ND1 & $11395-12333$ & 939 & - & -18 & ATA/TAA & 80.2 \\
\hline trnLeul (CUN) & $12334-12402$ & 69 & - & 0 & TAG & 87.0 \\
\hline$r r n L$ & $12403-13798$ & 1396 & - & 0 & - & 86.9 \\
\hline trnAla $(A)$ & 13799-13873 & 75 & - & 0 & TGC & 84.0 \\
\hline $\operatorname{trn} G \ln (Q)$ & 13879-13946 & 68 & + & 5 & TTG & 91.2 \\
\hline$r r n S$ & $13947-14802$ & 856 & - & 0 & - & 88.4 \\
\hline trnMet $(M)$ & $14803-14871$ & 69 & - & 0 & CAT & 84.1 \\
\hline Control region & $14872-15549$ & 678 & + & 0 & - & 84.4 \\
\hline
\end{tabular}

3 
Table 4 (on next page)

Mitochondrial genome structure of Ceroplastes rubens. 
1 Table 4:

2 Mitochondrial genome structure of Ceroplastes rubens.

\begin{tabular}{|c|c|c|c|c|c|c|}
\hline Gene & Position (bp) & Size (bp) & Direction & $\begin{array}{l}\text { Intergenic } \\
\text { nucleotides }\end{array}$ & $\begin{array}{l}\text { Anti- or } \\
\text { start/stop } \\
\text { codons }\end{array}$ & $\mathrm{A}+\mathrm{T} \%$ \\
\hline$C O X 1$ & $1-1527$ & 1527 & + & 42 & ATA/TAA & 80.4 \\
\hline trnLeu2 (UUR) & $1532-1600$ & 69 & + & 4 & TAA & 88.4 \\
\hline COX2 & $1601-2261$ & 661 & + & 0 & ATA/T- & 83.4 \\
\hline $\operatorname{trnLys}(K)$ & $2262-2328$ & 67 & + & 0 & CTT & 83.6 \\
\hline $\operatorname{trnAsp}(D)$ & $2325-2383$ & 59 & + & -4 & GTC & 93.2 \\
\hline ATP6 & $2411-3091$ & 681 & - & 27 & ATA/TAA & 89.7 \\
\hline$C O X 3$ & $3118-3891$ & 774 & + & 26 & ATA/TAA & 86.3 \\
\hline $\operatorname{trn} G l y(G)$ & $3894-3950$ & 57 & + & 2 & TCC & 94.7 \\
\hline ND3 & $3951-4286$ & 336 & + & 0 & ATA/TAA & 90.8 \\
\hline trnAla $(A)$ & $4291-4350$ & 60 & - & 4 & TGC & 91.7 \\
\hline $\operatorname{trn} A s n(N)$ & $4370-4424$ & 55 & + & 83 & GTT & 87.3 \\
\hline trnSerl $(A G N)$ & $4424-4469$ & 46 & + & -1 & GCT & 80.4 \\
\hline trnGlu $(E)$ & $4469-4522$ & 54 & + & -1 & TTC & 94.4 \\
\hline $\operatorname{trnTrp}(W)$ & $4527-4577$ & 51 & + & 4 & TCA & 94.1 \\
\hline ND5 & $4579-6189$ & 1611 & - & 56 & ATT/TAA & 88.3 \\
\hline trnHis $(H)$ & $6264-6320$ & 57 & - & 74 & GTG & 89.5 \\
\hline ND4 & $6325-7605$ & 1281 & - & 4 & ATA/TAA & 89.4 \\
\hline$N D 4 L$ & $7619-7963$ & 345 & - & 13 & ATT/TAG & 92.2 \\
\hline ND6 & $7980-8375$ & 396 & + & 16 & ATA/TAA & 89.6 \\
\hline trnPro $(P)$ & $8375-8433$ & 59 & - & -1 & TGG & 89.8 \\
\hline ATP8 & $8435-8524$ & 90 & - & 1 & ATA/TAA & 90.0 \\
\hline trnIle (I) & $8546-8612$ & 67 & + & 21 & GAT & 86.6 \\
\hline ND2 & $8613-9551$ & 939 & + & 0 & ATT/TAA & 91.5 \\
\hline $\operatorname{trnTyr}(Y)$ & $9558-9606$ & 49 & - & 6 & GTA & 87.8 \\
\hline $\operatorname{trnThr}(T)$ & $9608-9659$ & 52 & + & 1 & TGT & 90.4 \\
\hline СYTB & $9660-10736$ & 1077 & + & 0 & ATC/TAA & 85.0 \\
\hline $\operatorname{trn} G \ln (Q)$ & $10745-10796$ & 52 & - & 8 & TTG & 92.3 \\
\hline ND1 & $10823-11728$ & 906 & - & 86 & ATT/TAG & 86.5 \\
\hline$r r n L$ & 11729-12991 & 1263 & - & 0 & - & 90.7 \\
\hline$r r n S$ & $12992-13578$ & 587 & - & 0 & - & 87.9 \\
\hline Control region 1 & $13579-14408$ & 830 & + & 0 & - & 85.4 \\
\hline trnPhe $(F)$ & 14409-14476 & 68 & - & 0 & GAA & 79.4 \\
\hline Control region 2 & $14477-15276$ & 800 & + & 0 & - & 88.4 \\
\hline trnMet $(M)$ & $15277-15345$ & 69 & + & 0 & CAT & 82.6 \\
\hline
\end{tabular}

3 